\title{
Compatibility and Proprietary Standards: The Impact of Conversion Technologies in IT-Markets with Network Effects
}

\author{
Charles Zhechao Liu, ${ }^{1}$ Esther Gal-Or, ${ }^{2}$ Chris F. Kemerer, ${ }^{2}$ Michael D. Smith $^{3}$ \\ \{zhliu, esther, ckemerer\}@katz.pitt.edu, mds@cmu.edu
}

April 2009

Available from http://ssrn.com/abstract $=980726$

Acknowledgements: The authors thank Ramayya Krishnan, Marshall Van Alstyne, Senior Editor Sanjeev Dewan, the associate editor and referees for this journal, and seminar participants at Carnegie Mellon University, INFORMS, the ICIS Doctoral Consortium, and the Workshop on Information Systems and Economics (WISE) for valuable comments on this research. Smith thanks the National Science Foundation for generous support provided through CAREER award IIS-0118767.

\footnotetext{
${ }^{1}$ University of Texas at San Antonio, San Antonio, TX 78249

${ }^{2}$ Joseph M. Katz Graduate School of Business, University of Pittsburgh, Pittsburgh, PA, 15260

${ }^{3}$ School of Information Systems and Management, Carnegie Mellon University, Pittsburgh, PA 15213
} 


\title{
Compatibility and Proprietary Standards: The Impact of Conversion Technologies in IT-Markets with Network Effects
}

\begin{abstract}
$\underline{\text { ABSTRACT }}$
In markets that exhibit network effects, the presence of digital conversion technologies provides an alternative mechanism to achieve compatibility. This study examines the impact of conversion technologies on market equilibrium in the context of sequential duopoly competition and proprietary technology standards.

We analyze this question by departing from the extant literature to endogenize the decision to provide a converter and incorporate explicit negotiations between firms concerning the extent of conversion. We argue that these choices better reflect the environment facing firms in digital goods industries and find that these decisions change some of the established results in the literature.

Specifically, we find that unless network effects are very large, the subgame perfect equilibrium involves firms' agreeing to provide digital converters at a sufficiently low price to all consumers. At this equilibrium, both the entrant and the incumbent are better off since the provision of converters alleviates price competition in the market and leads to both higher product revenues and higher proceeds from the sale of converters. Moreover, under some circumstances the provision of converters is welfare enhancing.

These findings have important implications for research and practice in the adoption of new digital goods as the introduction of conversion technologies can reduce the social costs of standardization without compromising the benefits of network effects.
\end{abstract}

Keywords: Network Effects, Conversion Technologies, Compatibility, Technology Standards, Digital Goods. 


\section{Introduction}

In many information technology (IT) markets, network effects arise in compatible products where one user's consumption utility increases with the number of users adopting the same product (Liebowitz and Margolis 1994). ${ }^{1}$ When network effects are present, consumers benefit from compatibility since a large and standardized product network confers greater utility that would not be available in the absence of compatibility. From a societal standpoint, standardization across different product formats yields much larger social surplus than the sum of those obtained from several smaller product networks.

However, standardization can be difficult to achieve. Dominant firms may prefer not to be compatible with other products so that they can enjoy strategic advantages such as a higher price premium (Gandal 1994; Brynjolfsson and Kemerer 1996; Gallaugher and Wang 2002), faster market penetration (Kauffman et al. 2000; Zhu et al. 2006), and the possibility to control the design interface (Conner 1995). New entrant firms may be reluctant to adopt a dominant standard if standardization means sacrificing their unique product features or giving up much of their prior investments in product development. Moreover, the lack of standardization can result in significant private and social loss and reduced technology innovation (Farrell and Saloner 1986).

Amid concerns over tradeoffs between the benefits and associated costs from standardization, an alternative way to achieve compatibility may emerge from the market for digital goods (e.g., software, digital media). As the content carried by these products is in a digital format, communication between incompatible products can frequently be realized through a converter. For example, software can be used to convert music, image, and video files between different formats to play on different devices. ${ }^{2}$ Likewise, software virtualization applications can allow software written for one operating system to run on a different operating system. From the perspective of hardware, flash memory card readers can convert data between multiple incompatible flash memory standards, and there are a variety of hardware converters that allow game software written for one gaming platform to be played on competing platforms. In short,

\footnotetext{
${ }^{1}$ Classic examples are the telephone and fax markets where the value created by an $n$-node two-way network is on the order of $\mathrm{n} *(\mathrm{n}-1)$, also known as Metcalfe's Law (Gilder 2000).

2 Files protected with Digital Rights Management being a notable exception.
} 
the digital nature of these products (or their outputs) opens up the possibility of achieving compatibility without incurring significant costs or seriously degrading performance. ${ }^{3}$ When standardization is attained through converters, technology innovation and adoption are greatly facilitated, since firms can maintain their unique product features without the need to redesign their products, leading to greater product variety and minimal risk of stranding consumers on a non-dominant technology.

Despite the benefits of conversion, the provision of conversion technologies in the presence of network effects can be difficult. In many cases the original product developer is afforded control over digital product conversion through methods such as copyright and patent law, end user license agreements, and technology obfuscation. Moreover, in many IT markets, technology standards are introduced to the market sequentially, and once the incumbent firm has established a leading position in the market, it may not have an incentive to supply converters to consumers who purchase the incompatible formats. In the absence of a feasible market mechanism or a successful intervention to achieve coordination, how do firms agree on the provision of converters and compete in the presence of conversion technology? And how do converters affect consumer's adoption decisions and resulting social welfare?

In this research we address these questions in the context of proprietary technology competition. We develop a two-stage duopoly model to analyze the impact of digital converters on technology adoption and social welfare in a market characterized with network effects, sequential entry, and heterogeneous consumer preferences. More importantly, we examine the firms' incentives to provide converters when such provision requires joint agreement from both parties and when firms can strategically set the price of the converters. When the provision of converters is jointly determined, the division of proceeds from the sale of converters constitutes an important part of the negotiations. In particular, firms can strategically set the price of the converter to facilitate or block the adoption of converters. Therefore, we also introduce a mechanism through which firms can determine the extent of conversion and the allocation of proceeds from the sale of converters.

\footnotetext{
${ }^{3}$ This property is not typically observed in non-digital products. For example, in addition to the physical incompatibilities in their cassette formats, even video conversion between the VHS and Betamax standards was costly and resulted in signal degradation (Cusumano et al. 1992).
} 
The main results of the paper can be summarized as follows: supplying converters to all consumers is the unique subgame perfect equilibrium except when network effects are very large. At this equilibrium firms agree to charge a sufficiently low price for converters in order to encourage their adoption. Increasing converter adoption alleviates price competition among competing products, leading to higher product revenues. The entrant favors the provision of converters as it facilitates its market expansion and profit increase. However, even the incumbent has a strong incentive to supply converters, despite the fact that its first mover advantage is weakened by the adoption of converters. Finally, the provision of converters can be welfare enhancing when the period of competition among multiple technologies is sufficiently long in comparison to the initial monopoly period when a single technology dominates the market.

Our study relates to a small but growing literature on network effects and conversion technologies. The notion of a "gateway technology" was first presented by David and Bunn (1988) in a case study of how converters tipped the battle between AC and DC electrical systems. Subsequently, the role of converters on technology adoption has been primarily studied in the analytic literature. Incentives to provide converters have been found in complementary products markets when network effects are absent (Matutes and Regibeau 1988; Economides 1989). Farrell and Saloner (1992) were among the first to model converters in a market characterized with network effects. They found that, contrary to the common belief that converters can internalize the benefits from network effects in the market, the provision of converters is not welfare improving and, under some circumstances, the incumbent would prefer either not to supply converters or to make them costly. However, due to their focus on the welfare consequences of converters, the authors model consumers' adoption decisions by assuming that converters are exogenously available and arbitrarily adopted by any of the two product networks which are introduced to the market at the same time, characteristics that may not be applicable to digital goods markets. Extending this work, Choi develops an overlapping-generations model to analyze the role of converters in the transition process between incompatible technologies $(1996 ; 1997)$. The results from these studies suggest that the existence of converters does not necessarily facilitate the transition to a new technology as the availability of converters enhances not only the value of adopting the new technology, 
but also that of the existing technology, and allocation inefficiency may arise when consumers from the larger network have to bear the cost of converters.

Although the extant literature provides a general framework to study the impact of converters on technology adoption, several questions remain unanswered. First, the existing static framework of symmetric competition does not adequately capture a market characterized with sequential entry and dynamic price competition, characteristics common in digital goods markets. Moreover, in the rapidly evolving IT industry, the length of the initial monopoly period may be significantly shorter than the subsequent competitive period, and consumers' expectations may hinge critically on the length of the consumption period. These important features have not been adequately captured in the prior literature.

Second, most existing studies of conversion technology assume that converters are exogenously provided and the provision of converters does not require consent from firms who develop the incompatible technologies. Such assumptions neglect the importance of ownership embedded in many technology standards. Unlike traditional commodities, many technology standards are proprietary or protected by intellectual property laws. For example, media formats such as MP $3,{ }^{4}$ MPEG4 ${ }^{5}$ and $\mathrm{GIF}^{6}$ have all been granted patent protection; and while the GIF patents expired in 2003 and 2004, the MP3 and MPEG4 standards still require licensing agreements for use in software and hardware products. Many other hardware and software products, such as flash memory standards, video standards, or gaming platform standards, are also covered by patents and require licensing agreements for use. ${ }^{7}$ Similarly, the use of software in virtualization environments can be curtailed by the terms of end user licensing agreements. For example, when it was first released, the Vista End User License Agreement (EULA) prohibited installation in virtualization environments for all except the higher priced "Ultimate" and

\footnotetext{
${ }_{5}^{4} \mathrm{http}: / / \mathrm{mp} 3$ licensing.com/

5 http://mpegla.com

${ }^{6} \mathrm{http}: / /$ www.unisys.com/about_unisys/lzw

${ }^{7}$ For example, see the recent lawsuit in Japan by Nintendo and 54 other firms against the makers of the R4 Revolution, a converter that allows for playback of independent ROMs on the Nintendo DS handheld game console (Pell 2008).
} 
"Business" editions (see Cohen 2007). ${ }^{8}$ Finally, where intellectual property protection is less feasible, as in the case of some computer file formats, producers can use technology obfuscation to prevent conversion. $^{9}$

A third characteristic of digital environments is the production of conversion technologies typically requires joint agreement of the parties involved, and in many situations cannot be facilitated without coordination. Therefore, to ensure the validity of the results, it is important to explicitly examine firms' incentives to supply converters and the mechanism through which they reach such an agreement. For example, in 1997 Microsoft and Apple negotiated an agreement whereby Microsoft took a \$150 million equity stake in Apple and made a 5 year commitment to continue development of Microsoft Office for the Mac platform in exchange for Apple agreeing to make Internet Explorer the default browser on the Mac platform and dropping various patent and copyright infringement claims against Microsoft (see Ohlson and Paquet 1997). Highlighting the win-win nature of facilitating conversion in this setting, a 1999 Microsoft press release stated "Both companies agree that working together better serves their mutual customers. 'It's really when the tent pole went up, and we decided that Apple doesn't have to lose for Microsoft to win, and Microsoft doesn't have to lose if Apple wins,' [Microsoft Vice President of Developer Relations] Richardson said." 10

Finally, in the extant literature converters are often assumed to be exogenously provided, and as such the price of the converter is also assumed to be competitively determined and in most cases equals the marginal cost of production. Accordingly, proceeds from the sale of converters are absent from the decisions of the firms. However, in reality, firms can also profit from the sale of converters. Hence, they should take the proceeds of converters into account when negotiating with competitors on reaching an agreement on conversion. In order to capture the environment firms are facing, we incorporate the above

\footnotetext{
${ }^{8}$ The original End User License Agreement stating these terms is available from www.tinyurl.com/vistaeula (last accessed November 4, 2008). In January 2008, Microsoft changed their policy to allow virtualization for the lower priced home versions of Vista (see Niccolai and Snell 2008).

9 Some have suggested that Microsoft's specifications for its Word, Excel, and PowerPoint formats, which are 210, 118, and 349 pages long respectively, are examples of technology obfuscation. (Specifications are available from http://www.microsoft.com/interop/docs/OfficeBinaryFormats.mspx, last accessed November 4, 2008.)

10 See http://www.microsoft.com/presspass/features/1999/01-05apple.mspx, last accessed October 15, 2008.
} 
considerations in our model and examine how the market equilibrium changes when we relax these assumptions.

The rest of the paper is organized as follows: Section 2 describes the setup of the model and the mechanism to achieve conversion. Section 3 summarizes the equilibrium of the entire game and examines how the equilibrium outcome and social welfare change when relaxing various assumptions of the model. Section 4 discusses the findings and implications of this study. The analytical derivations and proofs are included in an Appendix.

\section{Model Setup and Preliminary Derivations}

\subsection{Assumptions of the Model}

Consider a two-stage game in which two incompatible durable goods, A and B, offered by firm A and firm B, respectively, compete in a market that exhibits network effects. Firm A enters the market in stage 1 and firm B enters the market in stage 2. Consumers have unit demand and the market size is normalized to 1 . The price set by firm $j \in\{A, B\}$ at stage $k \in\{1,2\}$ is designated by $P_{j k}$. Without loss of generality, marginal costs are assumed to be zero for both products A and B. Firm A can adjust the price of its product over time. Hence, $P_{A 1}$ may differ from $P_{A 2}$. In the first stage firm A is a monopolist, and in the second stage it competes against firm $\mathrm{B}$. The utility function of a consumer who buys product $j$ in stage $k$ is specified as:

$$
U_{j k}=r+\sum_{k}^{2} x_{j k}+\beta \sum_{k}^{2} M S_{j k}-P_{j k} \quad(0 \leq \beta<1),
$$

where $r$ is a consumer's reservation price ${ }^{11}$ for the general product category and $x_{j k}$ refers to a consumer's preference for the specific brand offered by firm $j$, which is independent of network size (Liebowitz and Margolis 1999). We also assume that consumers do not discount this network-size-independent utility, which implies that $x_{j 1}=x_{j 2}=x_{j}$. With the presence of network effects, a consumer is better off the larger

${ }^{11}$ We assume $r$ is sufficiently large so that the market is always fully covered. 
installed base to which she belongs. This positive consumption externality is captured by $\beta \sum_{k}^{2} M S_{j k}$ where $\beta$ measures the strength of the network effects ${ }^{12}$ and $M S_{j k}$ is the market size ${ }^{13}$ of firm $j$ in stage $k$.

Given that the network independent utility $x_{j}$ may vary among consumers, we let $x_{j}$ be uniformly distributed on the interval $[0,1]$. The consumer's location on this interval can be interpreted as the characteristics of the product she prefers best. As is typical in such models, we assume that the consumer's distance from the left end point of the interval measures her network-size-independent additional ${ }^{14}$ utility from product $\mathrm{A}, x_{A}$. Her distance from the right end point measures her network-size-independent additional utility from product $\mathrm{B}, x_{B}$, where $x_{B}=1-x_{A}$. Specifically, a consumer located at $x=s(s \in[0,1])$ enjoys a network-size-independent additional utility $s\left(x_{A}=s\right)$ if she purchases product A, and $1-s\left(x_{B}=1-s\right)$ if she purchases B. On the extremes, the consumer at $s=1$ has a network-size-independent added utility of 1 if she purchases product $\mathrm{A}$ and zero if she purchases product $\mathrm{B}$, and similarly for $s=0$. One can think of the consumer at $s=0$ as a "B-lover" and the consumer at $s=1$ as an "A-lover" (Figure 1).

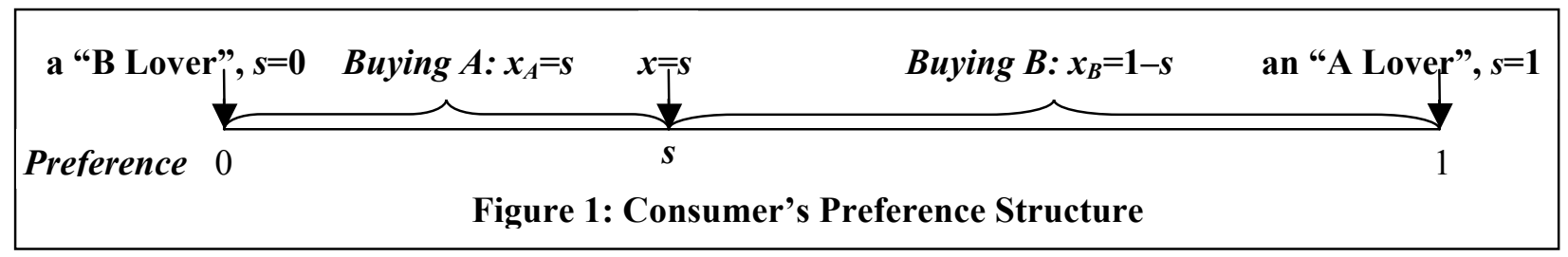

Envisioning that firm B will compete with firm A in stage 2, consumers face three choices: 1) buy product $\mathrm{A}$ in stage $1 ; 2$ ) buy product $\mathrm{A}$ in stage $2 ; 3$ ) buy product $\mathrm{B}$ in stage 2 . Because the product is durable, those who buy product A in stage 1 enjoy twice the network independent added utility and twice the network effect benefits. ${ }^{15}$

In order to derive the equilibrium, we designate the location of the consumer who is indifferent between buying product $\mathrm{A}$ in stage 1 and buying it in stage 2 as $i^{*}$ and the location of the consumer who is indifferent between buying products $\mathrm{A}$ and $\mathrm{B}$ in stage 2 as $s^{*}$. Following this notation, and the assumption

\footnotetext{
12 When $\beta>1$, the demand function may reverse direction and slope upward. In reality, we rarely observe network effects of such magnitude.

${ }_{13}$ As we normalize market size to $1, M S_{j k}$ also measures the market share of firm $j$ in stage $k$.

14 Added utility above the reservation price $r$.

15 For simplicity, we assume that $r$ is not doubled in this case. As mentioned earlier, the parameter $r$ is added to guarantee full market coverage. Specifically, $r$ is assumed to be large enough to ensure that the net payoff of each consumer is always positive.
} 
concerning the uniform distribution of the consumer's brand preference, we find that firm A's market size in stage $1\left(M S_{A 1}\right)$ and stage $2\left(M S_{A 2}\right)$ are: $1-i^{*}$ and $i^{*}-s^{*}$, respectively, and firm B's market size in stage 2 $\left(M S_{B}\right)$ is simply $s^{*}$ (Figure 2).

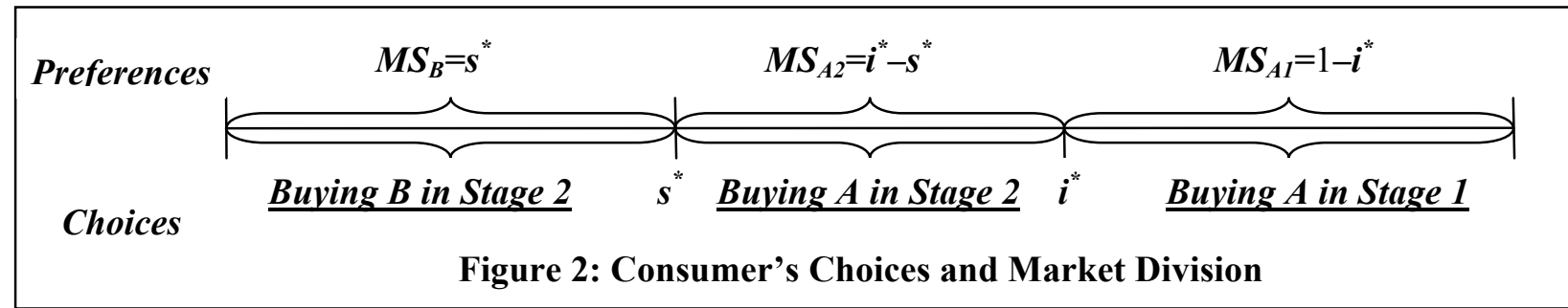

Table 1 shows the total utility that a type $s$ consumer derives from buying product $j$ in stage $k$.

Table 1: Consumer's Utility Function in the Baseline Model (without a converter)

\begin{tabular}{|c|c|c|}
\hline Consumer's Choice & Stage 1 & Stage 2 \\
\hline Buy A & $U_{A 1}=r+2 s+\beta\left(1-i^{*}\right)+\beta\left(1-s^{*}\right)-P_{A 1}$ & $U_{A 2}=r+s+\beta\left(1-s^{*}\right)-P_{A 2}$ \\
\hline Buy B & n/a & $U_{B 2}=r+(1-s)+\beta \bullet s^{*}-P_{B}$ \\
\hline
\end{tabular}

When product $\mathrm{B}$ enters the market in stage 2, the firms can jointly decide to offer converters that enable users of one of the products to communicate with users of the other incompatible technology, and exploit some network benefits from the rival network. We assume that the decision to supply converters is obtained via negotiation. ${ }^{16}$ Moreover, as a result of such negotiations, firms also jointly set the price for converters, which we designate by $C$. When converters are available, if a consumer chooses not to buy a converter, her utility function remains the same as in (1). But if she chooses to buy a converter, her utility function becomes:

$$
U_{j k}=r+\sum_{k}^{2} x_{j}+\beta \sum_{k}^{2} M S_{j k}-P_{j k}+\beta M S_{-j}-C
$$

\footnotetext{
${ }^{16}$ As outlined above, when any of the two technologies is proprietary or involves intellectual property rights, provision of converters frequently requires joint agreement from both firms. Examples given above include patent and licensing protection for a variety of media file types, licensing agreement protections for software operated in virtualization environments, and patent and copyright protection for hardware standards.
} 
where $\beta M S_{-j}$ captures the network benefits from the rival product's installed base. ${ }^{17}$ Obviously, a consumer will choose to buy a converter only if the conversion benefits outweigh the price of the converter $\left(\beta M S_{-j}>C\right)$.

The outcome of the negotiations between the firms in the second stage can take one of three forms: (1) No Conversion arises if firms fail to reach an agreement. In this case, both products remain incompatible with each other. (2) Partial Conversion arises if firms choose to offer converters at a high enough price so that only consumers from one of the two product networks find it optimal to buy a converter. Given firm A's first mover advantage, we will show that firm A's overall market share is always larger than that of firm B. Therefore, when the negotiated converter price satisfies $\beta M S_{B}<C \leq \beta M S_{A}$, only product B customers are willing to buy a converter. (3) Full Conversion arises when the firms make converters affordable to all consumers in the market. Specifically, when the negotiated converter price satisfies the inequality $C \leq \beta M S_{B}$, all customers find it optimal to buy a converter.

Following the negotiations, we assume that firms cannot collude on product prices. Instead, each firm chooses its product price to maximize its product revenue. Prices are chosen, though, after firms can observe the extent of conversion that the negotiations between them generate.

We describe the timeline of the model in Figure 3.

\footnotetext{
17 Prior studies often assume that converters are two-way, which means that users of incompatible products can communicate with each other without requiring both consumers to own converters. In other words, as long as a consumer owns a two-way converter, any consumer of the rival incompatible product can free-ride on this consumer's converter to communicate with this consumer. However, in reality, possession of converters is often required in order to take advantage of the conversion benefits, and the assumption of two-way converters tends to overestimate the impact of converters and simplify the adoption decision of converters. Therefore, to model the adoption of converters as an independent decision, we assume that these converters are one-way converters and a consumer has to purchase a converter in order to take advantage of the conversion benefits.
} 


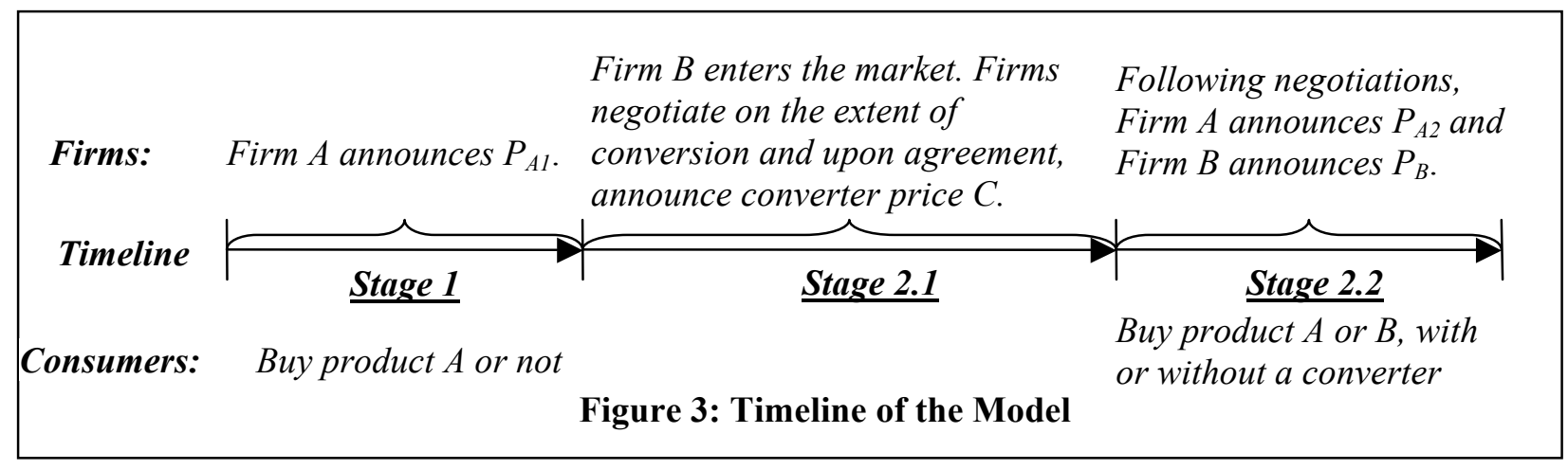

To model the negotiations, we use the Nash Bargaining Solution (Nash 1950). This solution concept implies that the payoff of each party consists of its "outside option" and half of the "gains from trade," if such gains are positive. The "outside option" coincides with the negotiating party's profits in case agreement cannot be reached. The "gains from trade" are calculated as the added joint benefit to the parties from reaching an agreement. ${ }^{18}$ In addition, as part of the negotiations, the price of the converter is chosen to maximize the joint payoff of the negotiating parties upon reaching an agreement. It is important to note, that firms can reach an agreement only if there are positive "gains from trade." Specifically, if $J^{N}$, $J^{P}$, and $J^{F}$ designate the firms' second stage joint payoff with No, Partial, and Full Conversion, then for Partial Conversion to arise it is necessary that: $J^{P}>J^{N} \Leftrightarrow \Pi_{A 2}^{P}+\Pi_{B}^{P}+C^{P^{*}} M S_{B}^{P^{*}}>\Pi_{A 2}^{N}+\Pi_{B}^{N}$, and for Full Conversion it is necessary that: $J^{F}>J^{N} \Leftrightarrow \Pi_{A 2}^{F}+\Pi_{B}^{F}+C^{F^{*}}\left(M S_{A}^{F^{*}}+M S_{B}^{F^{*}}\right)>\Pi_{A 2}^{N}+\Pi_{B}^{N}$, where the firms' joint payoff $J$ consists of profits from selling products in stage 2 as well as proceeds from the sale of converters (i.e., $C^{P^{*}} M S_{B}^{P^{*}}$ for Partial Conversion and $C^{F^{*}}\left(M S_{A}^{F^{*}}+M S_{B}^{F^{*}}\right)$ for Full Conversion).

Designating by $W_{j}^{A G R}$ the second stage payoff of firm $j$ upon reaching an agreement on conversion, the above discussion implies that:

\footnotetext{
18 If agreement between the parties generates a joint payoff of $J^{A G R}$, then at the Nash Bargaining Solution, the payoff allocated to the negotiator $j, W_{j}^{A G R}$, solves the maximization of the product $\left(W_{j}^{A G R}-W_{j}^{D I S}\right)^{1 / 2}\left(J^{A G R}-W_{j}^{A G R}-W_{-j}{ }^{D I S}\right)^{1 / 2}$, where $W_{j}^{D I S}$ and $W_{-j}{ }^{D I S}$ designate the "outside options", or disagreement payoffs of the two parties. This maximization yields the solution that $W_{j}^{A G R}=W_{j}^{D I S}+1 / 2\left(J^{A G R}-W_{j}^{D I S}-W_{-j}^{D I S}\right)$, as stated in the main text. The above maximization assumes that both parties have symmetric negotiating powers. To address asymmetric negotiating positions of the parties, the generalized Nash Bargaining Solution allows for an unequal division of the gains from trade $\left(J^{A G R}-W_{j}^{D I S}-W_{-j}{ }^{D I S}\right)$. We consider this case in a later section.
} 


$$
W_{j}^{A G R}=\left\{\begin{array}{l}
\Pi_{j}^{N}+\frac{1}{2}\left(\Pi_{j}^{P}+\Pi_{-j}^{P}-\Pi_{j}^{N}-\Pi_{-j}^{N}\right)+\frac{1}{2} C^{P^{*}} M S_{B}^{P^{*}} \text { with agreement on Partial Conversion, and } \\
\Pi_{j}^{N}+\frac{1}{2}\left(\Pi_{j}^{F}+\Pi_{-j}^{F}-\Pi_{j}^{N}-\Pi_{-j}^{N}\right)+\frac{1}{2} C^{F^{*}}\left(M S_{A}^{F^{*}}+M S_{B}^{F^{*}}\right) \text { with agreement on Full Conversion.. }
\end{array}\right.
$$

It may be interesting to consider how the above outcome is actually implemented. Following the agreement on conversion, the parties sell their products in the market, expecting profits of $\Pi_{j}^{P(F)}$ from such a sale. To obtain the agreement payoff described in (3), therefore, firm $j$ can expect the additional compensation $\left(W_{j}^{A G R}-\Pi_{j}^{P(F)}\right)$ as follows:

$$
T_{j}^{A G R}=\left\{\begin{array}{l}
\frac{1}{2} C^{P^{*}} M S_{B}^{P^{*}}+\left[\frac{1}{2}\left(\Pi_{-j}^{P}-\Pi_{-j}^{N}\right)-\frac{1}{2}\left(\Pi_{j}^{P}-\Pi_{j}^{N}\right)\right] \quad \text { for Partial Conversion, and } \\
\frac{1}{2} C^{F^{*}}\left(M S_{A}^{F^{*}}+M S_{B}^{F^{*}}\right)+\left[\frac{1}{2}\left(\Pi_{-j}^{F}-\Pi_{-j}^{N}\right)-\frac{1}{2}\left(\Pi_{j}^{F}-\Pi_{j}^{N}\right)\right] \quad \text { for Full Conversion. }
\end{array}\right.
$$

Hence, at the conclusion of the negotiations each party receives half of the proceeds from the sale of converters adjusted by an amount that depends on which party benefits more from reaching an agreement. If $\left(\Pi_{A 2}^{P(F)}-\Pi_{A 2}^{N}\right)<\left(\Pi_{B}^{P(F)}-\Pi_{B}^{N}\right)$, firm B benefits more from reaching an agreement than firm A. As a result, firm B will have to offer a "side payment" to firm A as measured by the second term of $T_{j}^{A G R}$ in (4). This second term reflects how much more reaching an agreement is valued by firm B than by firm A.

\subsection{Equilibrium of the Second Stage Game}

As we stated earlier, following the negotiations in the second stage, firms behave non-cooperatively when choosing prices for their products. Since we wish to focus on sub-game perfect equilibrium (SPNE), we start by considering the equilibrium prices selected by the firms in the second stage. The derivation of the equilibria varies based on the extent of conversion agreed upon by the firms at the beginning of the second stage. We begin with the equilibrium in the absence of agreement, namely, the "outside option" for firms. 
No Conversion: In stage 2, a consumer who is indifferent between buying product A without a converter or buying product B without a converter satisfies: ${ }^{19}$

$$
r+s^{*}+\beta\left(1-s^{*}\right)-P_{A 2}^{N}=r+1-s^{*}+\beta s^{*}-P_{B}^{N} \Rightarrow s^{*}=\frac{1+P_{A 2}^{N}-P_{B}^{N}-\beta}{2(1-\beta)} .
$$

In the second stage, firms take the market share established by the incumbent in the first stage as given. For a fixed $M S_{A I}=1-i^{*}$, their market shares in the second stage are $M S_{A 2}=i^{*}-S^{*}$ for A and $M S_{B}=s^{*}$ for B. The firms' maximization problems in stage 2 can therefore be written as:

$$
\left\{\begin{array}{l}
\underset{P_{A 2}^{N}}{\operatorname{Max}_{A 2}}=P_{A 2}^{N} M S_{A 2}^{N}=P_{A 2}^{N}\left(i^{*}-s^{*}\right)=P_{A 2}^{N}\left(i^{*}-\frac{1+P_{A 2}^{N}-P_{B}^{N}-\beta}{2(1-\beta)}\right), \\
\underset{P_{B}^{N}}{\operatorname{Max} \Pi_{B}^{N}}=P_{B}^{N} M S_{B}^{N}=P_{B}^{N}\left(s^{*}\right)=P_{B}^{N}\left(\frac{1+P_{A 2}^{N}-P_{B}^{N}-\beta}{2(1-\beta)}\right),
\end{array}\right.
$$

subject to the constraints that $0<s^{*} \leq i^{*}$, and $P^{*}{ }_{j k}>0$. Solving for the prices in terms of $i^{*}$ yields:

$$
\begin{aligned}
& \left.P_{A 2}^{N}\left(i^{*}\right)=\frac{\left(4 i^{*}-1\right)(1-\beta)}{3}\right), \\
& \left.P_{B}^{N}\left(i^{*}\right)=\frac{\left(2 i^{*}+1\right)(1-\beta)}{3}\right) .
\end{aligned}
$$

Since $M S_{B}^{N}\left(i^{*}\right)=s^{*}$ and $M S_{A 2}^{N}\left(i^{*}\right)=i^{*}-s^{*}$, we use (5) to obtain:

$$
\begin{aligned}
& M S_{A 2}^{N}\left(i^{*}\right)=\frac{4 i^{*}-1}{6}, \\
& M S_{B}^{N}\left(i^{*}\right)=\frac{2 i^{*}+1}{6} .
\end{aligned}
$$

Substituting (8), (9), (10), and (11) into (6) and (7) yields the firms' profits as a function of $i^{*}$ :

$$
\begin{aligned}
& \Pi_{A 2}^{N}\left(i^{*}\right)=\frac{\left(4 i^{*}-1\right)^{2}(1-\beta)}{18}, \\
& \Pi_{B}^{N}\left(i^{*}\right)=\frac{\left(2 i^{*}+1\right)^{2}(1-\beta)}{18} .
\end{aligned}
$$

And the firms' joint profits in the absence of converters are therefore given by:

$$
J^{N}\left(i^{*}\right)=\Pi_{A 2}^{N}\left(i^{*}\right)+\Pi_{B}^{N}\left(i^{*}\right)=\frac{(1-\beta)\left(10 i^{* 2}-2 i^{*}+1\right)}{9} .
$$

\footnotetext{
${ }^{19}$ From (1) and (2), it follows that if a consumer prefers buying A in stage 1 to buying A in stage 2, she will also prefer buying A in stage 1 to buying $\mathrm{B}$ in stage 2 since $U_{A I}\left(\mathrm{x}=i^{*}\right)=U_{A 2}\left(\mathrm{x}=i^{*}\right) \geq U_{A 2}\left(\mathrm{x}=s^{*}\right)=U_{B}\left(\mathrm{x}=s^{*}\right) \geq U_{B}\left(\mathrm{x}=i^{*}\right)$.
} 
Note that in order for the incumbent to charge a positive price and cover a portion of the remaining market in stage 2 , it must be true that $P_{A 2}^{N}\left(i^{*}\right)>0$ and $M S_{A 2}^{N}\left(i^{*}\right)>0$, hence $i^{*}>1 / 4$. If $i^{*}<1 / 4$, the incumbent covered a large portion of the market in stage $1\left(M S_{A 1}{ }^{*}=1-i^{*}>3 / 4\right)$ and the remaining market consists entirely of consumers who have such a strong preference for product B that the incumbent cannot attract any of them at a positive price.

Next we examine what happens if firms reach an agreement on conversion.

Partial Conversion: If, at the conclusion of the negotiations, the firms agree on charging a price for the converter that satisfies the inequality $\beta M S_{B}^{P}<C^{P} \leq \beta M S_{A}^{P}$, only product B customers are willing to buy a converter, as they are the only consumers whose conversion benefits outweigh the cost (due to firm A's relatively larger network size). In stage 2 , a consumer who is indifferent between buying product A without a converter and buying product $\mathrm{B}$ with a converter satisfies:

$$
r+s^{*}+\beta\left(1-s^{*}\right)-P_{A 2}^{P}=r+1-s^{*}+\beta s^{*}+\beta\left(1-s^{*}\right)-P_{B}^{P}-C^{P} \Rightarrow s^{*}=\frac{1+P_{A 2}^{P}-P_{B}^{P}-C^{P}}{(2-\beta)} .
$$

Similar to the No Conversion equilibrium, solving firms' stage 2 maximization problems yields firms' second stage prices, market shares and profits as a function of $i^{*}$ (summarized in Table 2).

Table 2: Partial Conversion Equilibrium Second Stage Prices, Market Shares and Profits*

\begin{tabular}{|c|c|c|}
\hline Price & $P_{A 2}^{P}=\frac{2 i^{*}(2-\beta)-\left(1-C^{P}\right)}{3}$ & $P_{B}^{P}=\frac{i^{*}(2-\beta)+\left(1-C^{P}\right)}{3}$ \\
\hline $\begin{array}{c}\text { Market } \\
\text { Share }\end{array}$ & $M S_{A 2}^{P}=\frac{2 i^{*}(2-\beta)-\left(1-C^{P}\right)}{3(2-\beta)}$ & $M S_{B}^{P}=\frac{i^{*}(2-\beta)+\left(1-C^{P}\right)}{3(2-\beta)}$ \\
\hline Profit & $\Pi_{A 2}^{P}=\frac{\left[2 i^{*}(2-\beta)-\left(1-C^{P}\right)\right]^{2}}{9(2-\beta)}$ & $\Pi_{B}^{P}=\frac{\left[i^{*}(2-\beta)+\left(1-C^{P}\right)\right]^{2}}{9(2-\beta)}$ \\
\hline $\begin{array}{c}\text { Joint } \\
\text { Profits }\end{array}$ & $J^{P}\left(i^{*}, C^{P}\right)=\Pi_{A 2}^{P}+\Pi_{B}^{P}+C^{P} \cdot M S_{B}^{P}=\frac{5 i^{* 2}(2-\beta)^{2}-2 i^{*}(2-\beta)\left(1-C^{P}\right)+2\left(1-C^{P}\right)^{2}}{9(2-\beta)}+\frac{C^{P}\left[i^{*}(2-\beta)+\left(1-C^{P}\right)\right]}{3(2-\beta)}$ \\
\hline
\end{tabular}

" In order for the Partial Conversion equilibrium to exist, firm A must be able to charge a positive price and have a positive market share in stage 2 , which requires: $i^{*}>\left(1-C^{\mathrm{P}}\right) /(4-2 \beta)$.

Note that the firms' second stage joint payoff is a function of the remaining market size $i^{*}$ that firm A didn't cover in stage 1 and the converter price $C^{P}$. When firms decide to supply a converter (i.e. when $J^{P}>J^{N}$ ), they choose an optimal converter price to maximize their second stage joint payoff, regardless of how the firms eventually divide the proceeds from converters. The Nash Bargaining solution described in 
(3) and (4) yields a higher payoff to each negotiator if actions are selected to maximize the joint payoff function. Observing the entries of Table 2 implies the comparative statics reported in Lemma 1:

Lemma 1: In a Partial Conversion equilibrium, as the price of the converter increases, the incumbent's second stage product price and market share increase $\left(\frac{\partial P_{A 2}^{P}}{\partial C^{P}}>0, \frac{\partial M S_{A 2}^{P}}{\partial C^{P}}>0\right)$, but the entrant's product price and market share both decline $\left(\frac{\partial P_{B}^{P}}{\partial C^{P}}<0, \frac{\partial M S_{B}^{P}}{\partial C^{P}}<0\right)$.

Lemma 1 implies that the strategic position of firm B is weakened in comparison to that of firm A if the price of the converter increases. Note that this might have counteracting effects on the proceeds from the sale of converters, since a decline in the market share of firm B implies that fewer consumer buy converters at the Partial Conversion equilibrium. To obtain the optimal price of the converters that maximizes the joint payoff function, we differentiate $J^{P}\left(i^{*}, C^{P}\right)$ from Table 2 to obtain the solution reported in Lemma 2.

Lemma 2: Agreement on Partial Conversion is feasible when ${ }^{20}$

$i^{*}>\operatorname{Max}\left\{\frac{1-\beta}{4-3 \beta}, \operatorname{Min}\left\{\frac{1}{3(2-\beta)}, \frac{1+\beta-\beta^{2}}{(2-\beta)(5-3 \beta)}\right\}\right\}$. The price of the converter is then chosen as follows:

$$
\begin{aligned}
& \text { When } \frac{3-\sqrt{3}}{3}<\beta<1 \text { and } \frac{1}{3(2-\beta)}<i^{*}<\frac{1+\beta-\beta^{2}}{(2-\beta)(5-3 \beta)}, \\
& C^{P^{*}}=C_{\mathrm{int}}^{P}=\frac{5 i^{*}(2-\beta)-1}{2}
\end{aligned}
$$

(ii) When $\beta<\frac{3-\sqrt{3}}{3}$ and $i^{*}>\frac{1-\beta}{4-3 \beta}$, or when $\frac{3-\sqrt{3}}{3}<\beta<1$ and $i^{*}>\frac{1+\beta-\beta^{2}}{(2-\beta)(5-3 \beta)}$,

$$
C^{P^{*}}=C_{\max }^{P}=\beta M S_{A}^{P}=\frac{\beta\left[(5-3 \beta)-i^{*}(2-\beta)\right]}{2(3-2 \beta)} .
$$

(Please see the Appendix for proof)

The bound on $i^{*}$ that supports Partial Conversion is implied, once again, by the requirement that the incumbent can obtain a positive market share in the second stage when charging a positive price.

\footnotetext{
${ }^{20}$ Notice that when $\beta<\frac{3-\sqrt{3}}{3}, \frac{1+\beta-\beta^{2}}{(2-\beta)(5-3 \beta)}<\frac{1}{3(2-\beta)}<\frac{1}{4-3 \beta}$, and when $\beta>\frac{3-\sqrt{3}}{3}, \frac{1+\beta-\beta^{2}}{(2-\beta)(5-3 \beta)}>\frac{1}{3(2-\beta)}>\frac{1-\beta}{4-3 \beta}$.
} 
According to Lemma 2, when the strategic position of firm A relative to that of firm B is very strong, either because network effects are strong (large $\beta$ values) or because firm A has established a significant market share in the first stage (small $i^{*}$ values), the firms' joint payoff is maximized when the price of the converter is chosen so that $\frac{\partial J^{P}\left(i^{*}, C^{P}\right)}{\partial C^{P}}=0$, thus obtaining the interior solution denoted by $C_{\mathrm{int}}^{P}$.

In contrast, when the strength of the network effects is moderate (small $\beta$ values) or if firm A's first stage market share is relatively small (large $i^{*}$ values), the price of the converter that maximizes the firms' second stage joint payoff is determined by the maximum willingness to pay on the part of consumers $\left(\beta M S_{A}^{P}\right)$. Smaller values of $\beta$ and/or bigger values of $i^{*}$ imply that the market share of firm A in stage 1 declines, thus reducing the network benefits that accrue to consumers who purchase converters. As a result, the value of $C^{P}$ that satisfies the condition $\frac{\partial J^{P}\left(i^{*}, C^{P}\right)}{\partial C^{P}}=0$ exceeds the maximum willingness to pay on the part of consumers.

It is interesting to note from the expressions obtained for $C^{P^{*}}$ in (16) and (17), that the optimal price of the converter chosen in the negotiations is initially an increasing function of $i^{*}$ for sufficiently small values of $i^{*}$. However, for larger values of $i^{*}$, the optimal converter price declines with $i^{*}$. Large values of $i^{*}$ have two counteracting effects on the pricing of converters. On the negative side, larger $i^{*}$ values reduce the overall market share of the incumbent, thus consumers of product B derive less benefit from conversion, and are willing to pay lower prices for it. On the positive side, larger $i^{*}$ imply that there is a bigger number of $\mathrm{B}$ customers who potentially will consider purchasing the converter for a given price. Such a parallel shift in demand can support charging higher prices for the converter ${ }^{21}$. According to Lemma 2 when $i^{*}$ is sufficiently large $\left(i^{*}>\operatorname{Max}\left\{\frac{1-\beta}{4-3 \beta}, \frac{1+\beta-\beta^{2}}{(2-\beta)(5-3 \beta)}\right\}\right.$, the former effect dominates and when $i^{*}$ is sufficiently small the latter effect dominates.

Substituting the optimal price of $C^{P^{*}}$ from (16) and (17) back into the joint payoff expression in Table 2 yields the following joint payoff of the firms as a function of the market share established by firm

\footnotetext{
${ }^{21}$ A parallel shift of a linear demand takes the form $\mathrm{P}=k a-b q$, where $q, b, k>0$ and $k$ is a scale parameter that shifts demand par-
} allel to itself. The revenue maximizing price for this demand is $\mathrm{P}^{*}=k a / 2$, which is higher the higher $k$ is. 
A in the first stage: ${ }^{22}$

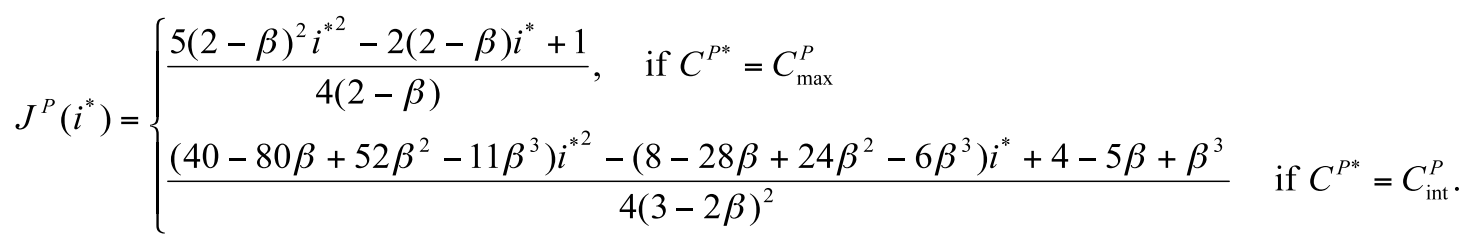

Full Conversion: If the firms choose a price for the converter so that $C^{F} \leq \beta M S_{B}^{F^{*}}$, the users of both products A and B are willing to buy a converter as conversion benefits outweigh the cost of conversion even for product A customers who benefit less from conversion. In stage 2, a consumer who is indifferent between buying product A with a converter and buying product B with a converter satisfies:

$$
r+s^{*}+\beta\left(1-s^{*}\right)+\beta s^{*}-P_{A 2}^{F}-C^{F}=r+1-s^{*}+\beta s^{*}+\beta\left(1-s^{*}\right)-P_{B}^{F}-C^{F} \Rightarrow s^{*}=\frac{1+P_{A 2}^{P}-P_{B}^{P}}{2} .
$$

As in the previous cases, following the negotiations product prices are determined non-cooperatively in the second stage. In Table 3, we derive the Nash equilibrium prices, market shares and profits of the second stage game (as a function of the market share established by firm A in the first stage).

Table 3: Full Conversion Equilibrium Second Stage Prices, Market Shares and Profits ${ }^{*}$

\begin{tabular}{|c|c|c|}
\hline & Firm A & Firm B \\
\hline Price & $P_{A 2}^{F}=\frac{4 i^{*}-1}{3}$ & $P_{B}^{F}=\frac{2 i^{*}+1}{3}$ \\
\hline Market Share & $M S_{A 2}^{F}=\frac{4 i^{*}-1}{6}$ & $M S_{B}^{F}=\frac{2 i^{*}+1}{6}$ \\
\hline Profit & $\Pi_{A 2}^{F}=\frac{\left(4 i^{*}-1\right)^{2}}{18}$ & $\Pi_{B}^{F}=\frac{\left(2 i^{*}+1\right)^{2}}{18}$ \\
\hline Joint Profits & $J^{F}\left(i^{*}, C^{F}\right)=\Pi_{A 2}^{F}\left(i^{*}\right)+\Pi_{B}^{F}\left(i^{*}\right)+C^{F}=\frac{1-2 i^{*}+10 i^{* 2}}{9}+C^{F}$ \\
\hline
\end{tabular}

${ }^{*}$ The condition necessary to support positive prices in the second stage is $i^{*}>1 / 4$.

Lemma 3: Under Full Conversion, neither the firms' prices nor their market shares depend on the price of the converter. However, the firms' second stage joint payoff is an increasing function of the price of the converter. As a result, in the negotiations, firms will find it optimal to charge the highest possible price that is consistent with Full Conversion, namely $C^{F^{*}}=\beta M S_{B}^{F^{*}}$.

Substituting $C^{F^{*}}$ into $J^{F}\left(i^{*}, C^{F}\right)$ yields the firms' second stage Full Conversion joint payoff: ${ }^{23}$

\footnotetext{
22 There is some abuse of notation in defining $J^{P}\left(i^{*}\right)$ since we dropped the second argument of $J^{P}(\cdot)$ from Table 2, after substituting the optimal value of $C^{P}$.

${ }_{23}$ As explained in footnote 15, here as well we dropped the second argument of $J^{P}(\cdot)$ from Table 3 in $\operatorname{defining} J^{P}\left(i^{*}\right)$.
} 


$$
J^{F}\left(i^{*}\right)=\frac{1-2 i^{*}+10 i^{* 2}}{9}+\frac{\beta\left(2 i^{*}+1\right)}{6} \text {. }
$$

Before comparing the joint payoff that accrues to the firms under the three levels of conversion, it is noteworthy from Tables 2 and 3 that for a fixed $i^{*}$, higher levels of conversion unambiguously increase the price the firm B charges. Full conversion leads also to a higher price charged by firm A in comparison to no conversion. However, the comparison of A's price under partial conversion with the other two conversion regimes is ambiguous and depends on the value of $i^{*}$.

In spite of this ambiguity, it follows from the Tables that the firms' joint revenue from product sales in the second stage unambiguously increase as the extent of conversion increases. Note that for a fixed $i^{*}$, this increase of revenues stems from the high network benefits, derived by consumers as a result of conversion and not from the fact that the two firms jointly select the price of the converter. In particular, for a fixed $i^{*}$, both firms raise their product prices when moving from no conversion to full conversion by a factor of $\beta$, which correspond to the additional network benefits derived by the consumers. For a fixed $i^{*}$, product prices under the two extreme conversion regions are completely independent of the converter price, implying that the higher product prices under full conversion stem from the firms sharing with the consumers the enhanced network benefits derived by them and not from the collusive role that joint pricing of the converter by the two firms may play. Since the two technologies are differentiated, the firms can use the brand loyalty of their customers to extract some of the added network benefits derived by them. However, we will later argue that the negotiations over the price of the converter do play an extra collusive role, since such negotiations affect the equilibrium values of $i^{*}$. Specifically, a higher level of conversion results in a higher value of $i^{*}$, which raises the product price derived in (8), (9), and the entries of Tables 2 and 3. We summarize the above discussion in Observation 1.

Observation 1: For a fixed value of $i^{*}$, (i) as the extent of conversion increases, firm B charges higher prices for its product. (ii) the firms' joint revenues from product sales in the second stage increase as the extent of conversion increases. 
In terms of the proceeds from the sale of converters, it follows from Tables 2 and 3 that Full Conversion leads to higher proceeds than Partial Conversion. Specifically, even though Full Conversion entails a lower converter price (i.e. $C^{P^{*}}>C^{F^{*}}=\beta M S_{B}^{F^{*}}$ ), the increased number of consumers buying converters more than compensates for the lower price, thus generating higher proceeds from the sale of converters. Hence, the demand of converters appears to be elastic, so that the percentage of increase in the number of consumers buying converters (equal to $\frac{i^{*}(2-\beta)+\left(1-C^{p^{*}}\right)}{\left[2 i^{*}(2-\beta)-\left(1-C^{P^{*}}\right)\right]}$ ) exceeds the percentage of reduction in the price of the converter (when $C^{P^{*}}=C_{\max }^{P}$, for instance, this percentage of decline is equal to $\left.\frac{2\left[2 i^{*}(2-\beta)-\left(1-C^{P^{*}}\right)-\left(2 i^{*}+1\right)(2-\beta)\right]}{2\left[2 i^{*}(2-\beta)-\left(1-C^{P^{*}}\right)\right]}\right)$. This is true for any value of $i^{*}$ that supports both conversion regimes. Observation 2 summarizes this fact.

Observation 2: For a fixed value of $i^{*}$, even though $C^{F^{*}}<C^{P^{*}}$, the proceeds from the sale of converters under Full Conversion is higher than under Partial Conversion. Specifically, $C^{F^{*}}>C^{P^{*}} \cdot M S_{B}^{P^{*}}$, implying that the demand for converters is elastic. (Please see the Appendix for proof of both observations)

The results reported in Observations 1 and 2 lead directly to the main result of our paper.

Proposition 1: For values of $i^{*}$ that can support all three different levels of conversion ${ }^{24}$, the following is true: $J^{F}\left(i^{*}\right)>J^{P}\left(i^{*}\right)>J^{N}\left(i^{*}\right)$.

Given that the joint payoff of the firms consists of proceeds from sale of products and converters, this joint payoff necessarily rises as the extent of conversion increases in view of Observations 1 and 2.

\section{Equilibrium of the Entire Game}

\subsection{The Maximization Problem of Firm A in the First Stage}

Given the results reported in Proposition 1, both firms and consumers anticipate Full Conversion in stage 2 . In stage 1 , the consumer located at $i^{*}$ is indifferent between buying product $\mathrm{A}$ in stage 1 and stage

\footnotetext{
24 Note that the region of the values of $i^{*}$ that support No or Full Conversion (i.e. $i^{*}>1 / 4$ ) does not coincide with the region supporting Partial Conversion. When $\beta<\frac{3-\sqrt{3}}{3}$, there is a larger range of $i^{*}$ values that support Partial Conversion, namely there are values of $i^{*}<1 / 4$ consistent with Partial Conversion. When $\beta>\frac{3-\sqrt{3}}{3}$, the range of $i^{*}$ that support No or Full Conversion may be bigger than that supporting Partial Conversion. This is the case, for instance, when $\beta>2 / 3$, in which case $\frac{1}{4}<\frac{1}{3(2-\beta)}<\frac{1+\beta-\beta^{2}}{(2-\beta)(5-3 \beta)}$.
} 
2 and satisfies the following equation:

$$
r+2 i^{*}+\beta\left(1-i^{*}\right)+\beta-P_{A 1}^{F}-C^{F}=r+i^{*}+\beta-P_{A 2}^{F}-C^{F} \Rightarrow P_{A 1}^{F}=i^{*}+P_{A 2}^{F}+\beta-i^{*} \beta .
$$

We rewrite firm A's expected payoff of both stages as:

$$
\underset{i^{*}}{\operatorname{Max}} \Pi_{A}^{F}=P_{A 1}^{F}\left(i^{*}\right) M S_{A 1}^{F}\left(i^{*}\right)+\left[\Pi_{A 2}^{N}\left(i^{*}\right)+\frac{1}{2}\left(J^{F}\left(i^{*}\right)-J^{N}\left(i^{*}\right)\right]\right.
$$

subject to the constraints that $0<i^{*} \leq s^{*} \leq 1, P_{j k}^{*}>0$, and the expressions for $P_{A 2}^{F}, M S_{A 2}^{F}$ and $P_{A 1}^{F}$ are given in Table 3 and by equation (21), respectively. ${ }^{25}$

The payoff in (22) is the sum of revenues from the sale of the product in the first stage and the payoff from Full Conversion in the second stage. The second stage payoff includes revenues from the sale of the product in the second stage, half of the proceeds from the sale of converters, and a possible side payment $^{26}$ from firm B to firm A. Combining these three sources of profit yields the Nash Bargaining outcome reported in the second term of (22). In the first stage, firm A chooses $P_{A 1}^{F}$ to maximize its payoff. It is simpler however to obtain the solution by maximizing over $i^{*}$ instead, given that the second stage prices and profits are all expressed in terms of $i^{*}$.

Optimizing (22) with respect to $i^{*}$ yields the equilibrium reported in Table 4. In Proposition 2 we report the comparative statics implied by the entries in Table 4.

Table 4: Full Conversion Equilibrium Prices, Market Shares and Profits

\begin{tabular}{|c|c|c|c|c|}
\hline & Firm A (Stage 1) & Firm A (Stage 2) & Firm B (Stage 2) & Converter \\
\hline Price & $P_{A 1}^{F^{*}}=\frac{\left(76-43 \beta+3 \beta^{2}\right)}{4(13-6 \beta)}$ & $P_{A 2}^{F^{*}}=\frac{(9-7 \beta)}{(13-6 \beta)}$ & $P_{B}^{F^{*}}=\frac{(22-13 \beta)}{2(13-6 \beta)}$ & $C^{F^{*}}=\frac{\beta(22-13 \beta)}{4(13-6 \beta)}$ \\
\hline \multirow{2}{*}{$\begin{array}{c}\text { Market } \\
\text { Share }\end{array}$} & $M S_{A 1}^{F^{*}}=1-i^{*}=\frac{3(4+\beta)}{4(13-6 \beta)}$ & $M S_{A 2}^{F *}=\frac{(9-7 \beta)}{2(13-6 \beta)}$ & \multirow{2}{*}{$M S_{B}^{F^{*}}=s^{*}=\frac{(22-13 \beta)}{4(13-6 \beta)}$} & \\
\cline { 2 - 4 } & $M S_{A}^{F C^{*}}=M S_{A 1}^{F C^{*}}+M S_{A 2}^{F C^{*}}=\frac{30-11 \beta}{4(13-6 \beta)}$ & & \\
\hline Profit & $\Pi_{A}^{F C^{*}}=\Pi_{A 1}^{F C^{*}}+\Pi_{A 2}^{N C^{*}}+\frac{J^{F C^{*}}-J^{N C^{*}}}{2}=\frac{120+12 \beta-23 \beta^{2}}{16(13-6 \beta)}$ & $\Pi_{B}^{F C^{*}}=\Pi_{B}^{N C^{*}}+\frac{J^{F C^{*}}-J^{N C^{*}}}{2}=\frac{968-732 \beta-196 \beta^{2}+183 \beta^{3}}{16(13-6 \beta)^{2}}$ \\
\hline
\end{tabular}

\footnotetext{
25 Note that we solve the game using backward induction because firm A cannot commit in stage 1 to its stage 2 price. This captures the environment described in Stokey (1979) for inter-temporal price discrimination and is consistent with the Coase (1972) conjecture that rational buyers can foresee the possibility of second period discounting.

${ }^{26}$ The side payment is equal to $\beta i(1-i) / 3$ which correspond to half of the additional benefit that firm B derives from reaching an agreement on full conversion relative to $\mathrm{A}$.
} 
Proposition 2: As the strength of network effects increases (higher values of $\beta$ ), the firms charge lower prices in both stages, the overall market share of firm A increases, and that of firm B decreases, and the price charged for the converter rises. The profits of firm A increase and those of firm B initially increase and decrease thereafter. However, the joint profits of the industry unambiguously rise as the strength of the network effects increases.

It's noteworthy that the last result reported in Proposition 2 contradicts that available in the literature, where it has been shown that overall industry profits in the absence of conversion declines with the strength of the network effects (see Farrell (1992) and equation (14) of our model). The main reason for the different result stems from the fact that the firms jointly set the price of the converter in a manner that allows them to successfully share the benefits from conversion derived by consumers. Since those benefits rise with $\beta$, joint industry profits increase as well, in spite of the fact that product prices decline as $\beta$ increases.

Substituting the equilibrium prices and market shares into the constraint necessary to support the Full Conversion equilibrium (i.e. $i^{*}>1 / 4$ ) implies that the Full Conversion equilibrium can be supported for all values of $\beta(0 \leq \beta<1)$. Nevertheless, one should note that other than being engaged in a two-stage competition, the incumbent also has the ability to capture the entire market in stage 1 . We now explicitly examine this possibility and compare it with the Full Conversion equilibrium.

Specifically, when network effects are sufficiently large, the incumbent can capture the entire market in stage 1 . This is analogous to the classic "winner-takes-all" outcome. To do so, the incumbent must ensure that the consumer located at $x=0$ (the "B-Lover") prefers buying product $\mathrm{A}$ in the first stage versus buying product B in the second stage, namely, $1-P_{B}^{D} \leq 2 \beta-P_{A 1}^{D} \Rightarrow P_{A 1}^{D} \leq P_{B}^{D}+2 \beta-1$, where superscript $D$ refers to market dominance.

As the lowest price the entrant can charge is $\varepsilon(\lim \varepsilon \rightarrow 0)$, the maximum price that the incumbent can set in order to dominate the market is $2 \beta-1$. This requires that $\beta>1 / 2$ in order to support a positive price. The incumbent's profit in this case equals $2 \beta-1$. Note that even though the incumbent captures the entire 
market, he must cut prices due to the threat of entry. ${ }^{27}$

Comparison between the profits from Market Dominance and the profits from Full Conversion reveals that Dominance profits are higher than Full Conversion profits only when network effects are very large (i.e. $\beta>0.982$ ). When network effects are not as strong (i.e. $\beta<0.982$ ), the incumbent has no incentive to take over the market as the overall profits from the Full Conversion equilibrium are higher than Dominance profits. This implies that:

Proposition 3: When $\beta<0.982$, Full Conversion emerges as the subgame perfect equilibrium. Otherwise, when network effects are sufficiently large (i.e. $\beta>0.982$ ), the incumbent prefers to dominate the entire market in the first stage.

\subsection{Is It Ever Optimal to Commit to Less Than Full Conversion?}

The analysis so far assumes that the incumbent cannot commit in the first stage to the level of conversion he will agree to in the second stage. In the absence of such a commitment, we have shown that Full Conversion is the only subgame perfect equilibrium that can arise as long as $\beta<0.982$. Next, we consider the possibility that the incumbent does have commitment power, and we examine whether in this case it will find it optimal to commit to partial or no conversion.

Specifically, we assume an additional, initial stage prior to the two stages of our original game. At this stage, the incumbent can commit to full, partial, or no conversion. In the first case, the commitment is that both its customers and those of the future competing technology will have access to each other's network. For example, the incumbent and the entrant will release their design interface specifications, communication protocols, or source code to each other so that they both can produce converters for their customers. In the second case, the commitment is that only customers of the competing technology will have access to the incumbent's technology but not vice versa. For example, as noted above Microsoft's End User License Agreement (EULA), allows virtualization of Windows on other operating systems,

\footnotetext{
27 We have also examined the feasibility of two other types of Dominance equilibria, namely, the incumbent may choose to serve some consumers in stage 1 and cover the remaining market in the second stage, or, he may cover the entire market in the second stage only. In either case, the incumbent must ensure that he is able to attract the "B-lover" who is located at $x=0$, which requires: $1-P_{B} \leq \beta-P_{A 2}$, or $P_{A 2} \leq P_{B}+\beta-1$. Since the entrant can always set a low price $\left(P_{B}<1-\beta\right)$ so that $P_{A 2}<0$, such Dominance equilibria cannot arise in our model.
} 
such as Mac OSX. However, Apple's EULA does not allow virtualization of Mac OSX on non-Mac operating systems (see Griffiths 2008). Finally, in the last case the incumbent commits not to allow any conversion at all. After this first stage, the game proceeds as before. In the second stage the incumbent, still a monopolist, set the price for its technology. At the beginning of the third stage, following the entry of the competing technology, negotiations on the converter's price takes place if the incumbent committed to allow some level of conversion in the first stage. Subsequently, the pricing of the technology by the incumbent and entrant takes place.

In Tables 5, 6, and 7 (included in the Appendix) we characterize the equilibrium outcomes when the incumbent commits to No Conversion (Table 5) and Partial Conversion (Tables 6 and 7), respectively. We find that the comparative statics of the solution are similar to those reported in Proposition 2. Specifically, as network effects become more important ( $\beta$ increases) firms price more aggressively, the market share and profits of firm A increase and those of firm B decrease. However, as reported in the following Lemma, the range of $\beta$ values that yield positive product prices and market shares for both firms in the competitive stage shrinks when the incumbent can commit to less than full conversion.

Lemma 4: The prices and market shares of both firms are strictly positive in the competitive stage when

(i) $0<\beta<0.6$ with No Conversion.

(ii) $0<\beta<0.717$ with Partial Conversion, in which case $C^{P^{*}}=C_{\max }^{P}$, or $0.958<\beta<1$, in which case $C^{P^{*}}=C_{\text {int }}^{P}$.

The discontinuity of the supported values with partial conversion is the result of the two separate ranges obtained for the negotiated price of the converter reported in Lemma 2.

The reason that a reduced level of conversion leads to a smaller range of $\beta$ values supporting a positive market share for firm A in the competitive stage can be explained by observing the entries of Tables 5, 6 and 7. A lower level of conversion results in more aggressiveness on the part of the incumbent in the second stage. Specifically, firm A prices more aggressively in order to obtain a bigger market share in this stage. As a result, price competition between the firms in the competitive stage may lead to negative prices over a wider range of $\beta$ values. In essence, a higher degree of conversion alleviates price competition in the competitive stage. The alleviated price competition stems from two sources. First, as 
argued before, because the technologies are differentiated, the firms can extract from the consumer some of the added conversion benefits they derive for a fixed value of $i^{*}$. In addition, the firms use the negotiated price of the converter as a collusive device to raise the equilibrium level of $i^{*}$ (i.e. to reduce the initial market share obtained by A). We summarize this finding in Observation 3 .

Observation 3: A commitment to a higher level of conversion results in a smaller market share obtained by firm A in stage 2 and higher product prices charged by both firms in stage 3 .

Next we compare revenues from the sale of converters under Partial and Full Conversion.

Observation 4: The price of the converter is lower, but the overall profits from the sale of converters are higher, under a commitment to Full rather than Partial Conversion.

The above observations lead to the result reported in Proposition 4:

Proposition 4: The incumbent will have no incentive to commit to less than Full Conversion even if it has the commitment power to do so. (Please see the Appendix for proof)

Even though Full Conversion is the preferred outcome (as long as $\beta<0.982$ ), it may sometimes not be feasible, for technical reasons, to provide converters to consumers. Comparing the entries of Tables 4 and 5 suggests that in the absence of converters both firms are worse off. We summarize this in Observation 5.

Observation 5: If the conversion technology is unavailable, the profits of both the incumbent and the entrant are lower than when the conversion technology is available.

Observation 5 implies also that if the potential entrant incurs fixed costs when entering the market, the availability of the conversion technology makes its entry more likely, given that the entrant can expect higher profits in this case.

It is noteworthy that our model differs from the case where firms strategically price their compatible but differentiated products separately. In our model firms benefit from conversion for two reasons. First when converters are available, price competition is alleviated; and second, firms can obtain additional proceeds from the sale of converters. However, in Table 8 of the Appendix, we illustrate that even when 
converters are available to consumers at no charge, both firms still benefit from their availability. Hence, even though firms cannot use the price of the converter as a collusive device in this case, they can still increase their profits by extracting from the consumers a portion of their added network benefits. ${ }^{28}$

\subsection{Comparison of Social Welfare}

In this section we investigate the properties of the solution that maximizes social welfare (designated by $T S$ ), where welfare is calculated as the sum of consumer and producer surplus. Given the absence of any production costs in our model, social welfare is calculated as the average gross benefit derived by consumers before subtracting any expenditure on products and converters. Since the expenditure of the consumers comprises the revenues of the producers, all such expenses cancel out in the calculation of social welfare. We obtain, therefore:

$$
T S= \begin{cases}r+\left[\beta+\beta\left(1-i^{*}\right)^{2}\right]+P D\left(s^{*}, i^{*}\right) & \text { under Full Conversion, } \\ r+\left[\beta s^{*}+\beta\left(1-s^{*}\right)^{2}+\beta\left(1-i^{*}\right)^{2}\right]+P D\left(s^{*}, i^{*}\right) & \text { under Partial Conversion, } \\ r+\left[\beta\left(s^{*}\right)^{2}+\beta\left(1-s^{*}\right)^{2}+\beta\left(1-i^{*}\right)^{2}\right]+P D\left(s^{*}, i^{*}\right) & \text { under No Conversion. }\end{cases}
$$

where $P D\left(s^{*}, i^{*}\right)=s^{*}\left(1-\frac{s^{*}}{2}\right)+\frac{i^{* 2}-s^{* 2}}{2}+\left(1-i^{* 2}\right)$.

Social welfare consists of the sum of three components: product reservation price $r$, the average network benefits derived by consumers, and the average brand specific benefits derived by consumers (designated by $P D$ to capture the benefits from product differentiation). In Proposition 5 we characterize the solution that maximizes social welfare in our setting.

Proposition 5: (i) Social welfare is maximized with Full Conversion, when all consumers have access to converters. The optimal segmentation of the market at the maximum is given as:

$$
i_{T S}^{*}=s_{T S}^{*}= \begin{cases}\frac{1-2 \beta}{3-2 \beta}, & \text { if } \beta \leq \frac{1}{2} \\ 0 & \text { if } \beta>\frac{1}{2}\end{cases}
$$

(ii) The maximum total surplus can be expressed, therefore as:

\footnotetext{
28 In comparison to a regime with No Conversion, the availability of free converters raises A's profits if $0<\beta<0.723$, B's profits if $0<\beta<0.928$, and joint industry profits if $0<\beta<0.808$. Since No Conversion can be supported only if $0<\beta<0.6$, it follows that the availability of converters benefit both firms for all $\beta$ values supporting both regimes.
} 


$$
T S^{*}=\left\{\begin{array}{ll}
r+\beta+\frac{\left(21-20 \beta+4 \beta^{2}\right)}{2(3-2 \beta)^{2}} & \text { if } \beta \leq \frac{1}{2} \\
r+\beta+1+\beta & \text { if } \beta>\frac{1}{2} .
\end{array} \quad\right. \text { (Please see the Appendix for proof) }
$$

It is noteworthy that the extent of segmentation that is welfare maximizing is far more limited than that obtained at the market equilibrium. In particular, all the consumers who wish to buy product A should do so in the first stage in order to maximize welfare. Moreover, when $\beta>1 / 2$, no consumer should purchase product B. Essentially, the extent of heterogeneity in preferences that we introduce in our model is relatively small in comparison to the network benefits. Since consumers who purchase the product early derive those benefits over a longer period of time, the welfare maximizing outcome sometimes dictates (when $\beta>1 / 2$ ) that firm A should dominate the market. The added benefit from prolonged use of the product more than outweighs the disutility of consumers who strongly prefer product B (those located close to zero on the line).

Comparing the solution described in Proposition 5 with the entries of Table 5 implies that even if firm A can commit never to agree on conversion, the market share of firm B at the market equilibrium is in excess of the optimal social welfare outcome. Since increasing the extent of conversion raises the market share of firm B even further, it follows that increased conversion may not always be welfare enhancing $\left(M S_{B}^{F^{*}}>M S_{B}^{N^{*}}>\frac{1-2 \beta}{3-2 \beta}\right)$. On the positive side, a higher extent of conversion enhances the network benefits of consumers. On the negative side, it reduces the market share of the dominant firm, thus distorting market segmentation further away from welfare maximization.

Note that the above discussion is valid only when all consumers buying product A do so in the first stage. If some consumers buy $\mathrm{A}$ in the second period, it is no longer clear that an increase in the market share of B hampers efficiency. Consider, for instance, the case that the value of $i^{*}$ has already been fixed in the first stage and $i^{*}>0.5$, namely, fewer than half of the consumers adopted A's technology in the first stage. When $i^{*}$ is fixed, partial optimization of (23) with respect to $s^{*}$ yields $0.5=s^{*}<i^{*}$. Note that even with full conversion the market share of B derived in Table 4 falls short of 0.5 . Hence, increasing the market share of B, in this case, will actually enhance efficiency. 


\subsection{Extensions of the Baseline $\mathrm{Model}^{29}$}

In the previous analysis, we assumed that the two stages of competition are of equal length. However, in the rapidly evolving IT industry, due to fast technology improvement, the initial monopoly period is likely to be much shorter than the subsequent competitive phase in which consumers realize utility over a longer period time. To capture this characteristic of the IT market and to examine how the length of the different phases of the game affect the results obtained earlier, we multiply consumer's second stage utility both from the specific brand and the size of the network by a scaling parameter $k(k>1)$.

In this extended model, all the results obtained from the second stage game remain unchanged as $k$ has the same multiplicative impact on all second stage prices and profits. ${ }^{30}$ Hence, Full Conversion in stage 2 remains the only subgame perfect equilibrium outcome. In the first stage, firm A chooses $i^{*}$ (or alternatively $P_{A 1}^{F}$ ) to maximize the following objective function:

$$
\underset{i^{*}}{\operatorname{Max}} \Pi_{A}^{F}=\left[i^{*}+k P_{A 2}^{F}\left(i^{*}\right)+\beta\left(1-i^{*}\right)\right]\left(1-i^{*}\right)+k\left\{\Pi_{A 2}^{N}\left(i^{*}\right)+\frac{1}{2}\left[J^{F}\left(i^{*}\right)-J^{N}\left(i^{*}\right)\right]\right\} .
$$

The first term of (24) captures the revenues that accrue from product sale in the first stage. Note, however, that because of the longer duration of the second stage, second stage prices are multiplied by $k$. As a result, the expression for the first stage price in terms of $i^{*}$ becomes $P_{A 1}^{F}\left(i^{*}\right)=i^{*}+k P_{A 2}^{F}\left(i^{*}\right)+\beta\left(1-i^{*}\right)$, where $P_{A 2}^{F}\left(i^{*}\right)$ is expressed in Table 3 for the case of $k=1$. The second term of (24) is the second stage payoff firm A can expect, given the anticipation for a Full Conversion agreement. The expressions for $\Pi_{A 2}^{N}\left(i^{*}\right), J^{N}\left(i^{*}\right)$, and $J^{F}\left(i^{*}\right)$ are obtained from equations (12), (14) and (20), respectively. Once again, the second stage payoff is multiplied by $k$ due to the longer duration of consumption. Optimizing (24) with respect to $i^{*}$ yields the following solution:

$$
i^{F^{*}}=\frac{k(22+9 \beta)+18(1-2 \beta)}{2[k(8+6 \beta)+18(1-\beta)]} .
$$

From (25) it follows that as the length of the competitive phase increases relative to the length of the

\footnotetext{
${ }^{29}$ We thank an anonymous referee for these suggested extensions.

${ }^{30}$ Please see the derivation of this property in the Appendix.
} 
monopoly phase, the incumbent is willing to restrict himself to a smaller market share in stage $1\left(\frac{\partial F^{* *}}{\partial k}>0\right)$

in return for greater dividend in stage 2 . As a result, equilibrium prices in the competitive phase rise.

Note also that as the length of the competitive period increases, the segmentation that maximizes social welfare awards an increasingly larger market share to firm B. Specifically, to maximize welfare:

$$
i_{T S}^{*}=s_{T S}^{*}= \begin{cases}\frac{k-2 \beta}{1+2 k-2 \beta}, & \text { if } \beta \leq \frac{\mathrm{k}}{2} \\ 0 & \text { if } \beta>\frac{\mathrm{k}}{2} .\end{cases}
$$

From Table 5, in the absence of conversion, $M S_{B}^{N^{*}}=\frac{9-15 \beta}{26(1-\beta)}$. This market share is smaller than $s_{T S}^{*}$ for sufficiently large values of $k$. Hence increasing the extent of conversion, in this case, may imply not only improved network benefits but also an allocation of market shares that is closer to the welfare maximizing outcome. ${ }^{31}$ The last observation follows since increasing the extent of conversion leads to a larger market share for firm B. This outcome differs from that reached in the analysis in Farrell and Saloner (1992) in which they found that converters always lead to excessive adoption of the new technology. The main reason for this difference is that we adopt a dynamic setup in our model and allow for the length of the competitive period to be longer than the initial monopoly period, a structure not examined in Farrell and Saloner (1992). As the competitive period becomes longer, the extended potential benefits from conversion and product differentiation imply that the coexistence of the old and new technologies is welfare enhancing. Moreover, in Farrell and Saloner's (1992) model, conversion is assumed to be costly and imperfect, assumptions more likely to be true in an environment with analog devices. In a digital environment, we believe that the assumption of perfect conversion is a truer approximation of reality. ${ }^{32}$

Next we consider another possible extension of our model that is related to the sharing rule utilized by firms in allocating the "gains from trade" in the negotiations. So far we assumed that the firms agree to

31 Recall that this comparison is valid assuming that all A's customers buy the technology in the first stage.

32 Note, however, that we believe that our equilibrium and welfare analysis will remain qualitatively unchanged even with an imperfect conversion technology. As long as the degree of imperfection is sufficiently small, equilibrium product prices are higher if converters are available, thus providing incentives to the firms to reach an agreement to adopt converters, especially if they can receive the proceeds from the sale of converters. 
share those gains equally. However, the generalized Nash Bargaining Solution ${ }^{33}$ facilitates capturing asymmetry in the bargaining positions of the negotiators. In particular, if $\alpha$ is the share of the "gains from trade" allocated to firm A and $\alpha>1 / 2$, then firm A has a stronger negotiating position than firm B. It is very easy to show that as $\alpha$ increases, firm A behaves less aggressively in the first stage. Specifically $\frac{\partial i^{F^{*}}}{\partial \alpha}>0$, implying that the incumbent firm establishes a smaller market share in the first stage, thus leading to alleviated price competition in the second stage. Since the incumbent anticipates obtaining a larger share of the surplus when reaching an agreement on conversion, it has the incentive to foster a more cooperative environment in the second stage, which is feasible by cutting back on its extent of market coverage in the first stage. The effect of the more cooperative environment on social welfare may still be ambiguous, however, due to the enhanced market share of technology B that cooperation yields.

Another possible extension of our model is to allow for discrimination in the pricing of converters. Firms can agree to charge the customers of technology A, a different price than that charged the customers of B. Since A's customer derive lower benefits from conversion, they are likely to pay a lower price than B's customers, if discrimination in pricing is feasible. Moreover, price discrimination can facilitate improved extraction of consumer surplus and higher proceeds from the sale of converters. In fact, one possible environment in which price discrimination is actually indirectly implemented is when an incumbent technology offers to license its technology to an entrant for some payment. This licensing agreement is similar to the Full Conversion equilibrium we derive in our model, with the exception that the two technologies are not differentiated. In the case of licensing, the customers of newer technology B do not pay separately for the converter as its cost is indirectly included in the price of technology B. The customers of the incumbent technology A do not pay for conversion at all. Hence, there is implicit price discrimination between the two groups of customers. Note that similar to our model, in their negotiations to determine the licensing fee, the firms can use this fee as a device to foster collusion in the competitive stage.

33 Using the notation of footnote 11, the payoff allocated to negotiator $j$ in this case, $W_{j}^{A G R}$, is a maximizer of $\left(W_{j}^{A G R}-W_{j}^{D I S}\right)^{\alpha}\left(J^{A G R}-W_{j}^{A G R}-W_{-j}^{D I S}\right)^{1-\alpha}$, where $\alpha$ is the bargaining power of negotiator $j$. 


\section{Discussion}

In our model, we analyze the role of converters in shaping the dynamic competition between two incompatible technologies when network effects are present. While incorporating explicit negotiations between the firms, we show that when firms can jointly determine the price of the converter the subgame perfect equilibrium of the resulting competition involves firms setting the converter price low enough so that all consumers in the market find it optimal to purchase a converter. Moreover, this conversion equilibrium can be achieved in a way that is revenue enhancing for both the incumbent and the entrant.

This finding is consistent with anecdotal evidence that firms choose not to utilize the protections available to them. For example, while Unisys initially sought to aggressively enforce their patents on the GIF image standard, their stance met with a great deal of resistance (see Crotty 1995), led to the development of competing image standards (see Roelofs 1999), and ultimately led to Unisys reducing their licensing fees and dropping them altogether for individual website designers. ${ }^{34}$ Most subsequent patent holders for media standards have avoided this controversy by adopting low cost licensing structures for use of their patents, with examples including the MP3, PNG, and MPEG4 standards. ${ }^{35}$ This has led to the widespread availability of free and low cost software programs facilitating conversion between audio, image, and video file types. Likewise, in the context of protection under end user license agreements, as we noted above, Microsoft dropped restrictions in its end user license agreement that prohibited virtualization of its operating system on other competing operating systems. Finally, in the context of alleged technological obfuscation, Microsoft abandoned its complicated and proprietary file format for the ISO/IEC Open XML file standard. ${ }^{36}$

In contrast to prior literature on converters, we endogenize the firm's decision to provide converters. We believe endogenizing this decision is essential to model converters in IT environments where firms frequently can impose intellectual property or technological control over the development of converters.

\footnotetext{
${ }^{34}$ See http://www.unisys.com/about_unisys/lzw/lzw_license_english.htm, last accessed November 4, 2008.

35 See licensing information for MP3 and MPEG4 at http://mp3licensing.com/ and http://www.mpegla.com/ respectively. As noted by Roelofs (1999), the PNG standard was designed to be "patent-free" and does not require license fees for use.

${ }^{36}$ See http://www.iso.org/iso/pressrelease.htm?refid=Ref1 123 (last accessed April 9, 2009).
} 
Allowing for an endogeneous decision yields several important findings that differ from those obtained in earlier analyses.

First, we find that instead of making the converters costly, as shown in Farrell and Saloner (1992), in our model firms will provide converters at a sufficiently low cost to encourage extensive adoption of converters. Since the competing technologies are differentiated, the firms can utilize the brand loyalty of their customers to share some of the consumers' network benefits from conversion. ${ }^{37}$ Moreover, it is possible to imagine that the firms can use the joint agreement on conversion as a collusive device to further alleviate price competition between the two technologies.

Second, prior studies suggest that, due to the significant development costs and the time it takes for firms to reach an agreement, converters are rarely available in the nascent stage of a new technology (David and Bunn 1988, Choi 1996). As a result new technology adoption can be hindered, which further delays the adoption of converters (Choi 1997). However, we find that unless network effects are sufficiently high, the incumbent will choose to support full conversion even when it has the ability to commit to less than full conversion. Hence, our study predicts that both firms and consumers can anticipate successful negotiations on conversion, thus allowing them to be well prepared for the provision of converters. For example, while not perfectly analogous, this outcome is consistent with Adobe's strategy in introducing the Digital Negative (DNG) format in an effort to promote it as the standard for the raw files generated by various digital cameras. At its introduction Adobe provided a free DNG converter, which easily translates raw files from many of today's popular cameras. Following this move many software and digital camera manufacturers have developed support for the DNG format, which provides a strong signal to the industry that DNG may emerge as a de facto standard for the digital photo raw formats. As a result, the market penetration of the DNG format has risen significantly in the three years after launch. ${ }^{38}$

\footnotetext{
37 Table 8 of the Appendix shows that even when converters are available to consumers at no extra charge both firms may benefit from full conversion.

${ }^{38} \mathrm{http}: / / w w w . a d o b e . c o m / p r o d u c t s / d n g /$ supporters.html
} 
With regard to the impact of converters on social welfare, we find that in a digital environment the welfare implication of the availability of converters depends critically on the relative length of the competitive versus the monopoly periods. When the competitive period is sufficiently long, the availability of converters can be welfare enhancing. We believe this modeling decision captures the reality of IT-based markets where different technologies emerge rapidly and where new products can have a longer product lifecycle. Hence, the provision of converters can be critical in a digital world as the conversion benefits are realized over a longer period of time.

The potential social welfare benefits of conversion can also be seen in a variety of regulatory decisions by governments around the world. For example, in the United States, the Federal Trade Commission's decision to allow the merger between XM and Sirius satellite radio systems should facilitate de facto conversion between these two standards.

Finally, we find that the adoption of converters can increase the likelihood of survival of the entrant, since the higher profits that can be anticipated with conversion, thus leading the incumbent to compete less aggressively and creating an environment that is conducive for the adoption of converters. With alleviated price competition, the possibility of blockading the transition to a new technology, which is identified in Choi (1996), is less likely to emerge in our model. This finding is best illustrated in the flash memory card market where in the presence of the conversion technologies, new entrant formats were able to survive the initial competition and in some cases outperform the incumbent formats (Liu et al. 2007). In addition to these findings we also explore several issues of significant practical value that have not been examined in the prior literature, and that result in useful guidance for firms participating in such markets. For example, the proposed Nash Bargaining Solution to describe the process of negotiations offers a feasible mechanism for firms to implement an outcome whenever joint agreement of all parties is essential in achieving this outcome. Furthermore, the findings we derive for the equilibrium with Partial Conversion are particularly salient when technical feasibility permits only conversion from one technology to the other, but not vice versa (i.e. when the new technology can be made backward compatible through a converter but the old technology cannot be made forward compatible through a 
converter). This is because in this setting partial conversion will emerge as the equilibrium as it generates higher profits for firms than no conversion does. Moreover, firms developing new products are often confronted with tradeoffs between design improvement and backward compatibility. When backward compatibility can be achieved through a converter, our results enable managers to optimally price the converter and better predict the anticipated payoffs prior to making a design decision.

The findings of our model also shed light on the evolution of technology adoption in IT markets characterized with network effects and sequential entry. In the absence of a feasible mechanism to achieve compatibility, the prior literature has shown that once the incumbent has accumulated a significant customer base, the growth of the industry will fall into a self-reinforcing positive feedback loop. This may be costly to society as the dominant technology may not represent optimal technical performance (Farrell et al. 1992). Under this scenario technology innovation will be retarded, as potential entrants generally consider it too costly and time-consuming to enter into such a market (Au and Kauffman 2001), and a smaller than optimal network size may arise due to the motivations of monopolists to restrict output and raise prices (Economides and Himmelberg 1995; Sundararajan 2004).

However, when converters are widely available, new entrants can use these converters to take advantage of the network effects from the incumbent's installed base, thus extending the lifecycle of their products. Consequently, consumers can expect a lower risk of being stranded on a new technology, which in turn, leads to faster technology adoption and innovation. At the same time, if firms can achieve compatibility through a lower cost converter, the choice of a standard may rely more heavily on other factors, including, perhaps, brand and quality-related attributes, rather than simply the size of its installed base, thus increasing the possibility of the optimal technology being chosen as the industry standard.

Our findings also lend important theoretical support to policy promoting converters as a way to improve social welfare. Ideally, society can attain industry-wide compatibility through market forces or through a voluntary industry agreements. However, history has shown that it is often very difficult for the industry to unanimously agree upon a standard. 
For example, the costs of the Blu-ray and HD DVD standards war illustrate the importance of a feasible mechanism to achieve compatibility in IT markets. Technological limitations associated with lasers prevented low cost conversion between these two standards and the result was significant losses to Toshiba in product development and promotion, as well as delays in consumer adoption of both technologies (McBride et al. 2008). If converters had been technologically feasible in this market, new product development and market entry would have been greatly facilitated, and the standardization of the next generation DVD would have been smoother as consumers would be expected to be more aggressive in adopting the new product, leading to a faster market penetration.

As a result of these standardization challenges, social planners have been confronted with a dilemma between standardization, with its attendant social benefits, and the possible antitrust concerns that arise when enforcing standardization leads to the exercise of monopoly power by firms. It is interesting to observe that European regulators have aggressively sought to allow conversion and interoperability between incompatible media standards, while United States regulators have been less aggressive. For example, in Europe regulators have sought to open Apple's proprietary iTunes standard, whereas in the United States Apple has been free to choose its own approach to the business (see Gohring 2006). In either case regulatory measures might produce a net negative impact on either technology progress or social welfare.

Finally, we believe that this area offers a fruitful environment for future empirical and analytic research. Such research should pay careful attention to changing conditions in the technical or legal environment surrounding network effects and the provision of converters. As the move to digital converters has had important implications for prior models, which were based in an analog environment, future changes in the conversion environment may alter the results reached here. 


\section{References:}

Au, Y. A. and R. J. Kauffman 2001. Should We Wait? Network Externalities, Compatibility, and Electronic Billing Adoption. Journal of Management Information Systems 18(2): 47-63.

Brynjolfsson, E. and C. F. Kemerer 1996. Network Externalities in Microcomputer Software: An Econometric Analysis of the Spreadsheet Market. Management Science 42(12): 1627-1647.

Choi, J. P. 1996. Do Converters Facilitate the Transition to a New Incompatible Technology? A Dynamic Analysis of Converters. International Journal of Industrial Organization 14(6): 825-835.

Choi, J. P. 1997. The Provision of (two-way) Converters in the Transition Process to a New Incompatible Technology. Journal of Industrial Economics 45(2): 139-153.

Coase, R. H. 1972. Durability and Monopoly. Journal of Law \& Economics 15(1): 143-149.

Cohen, P. 2007. Vista Home License Forbids Virtualization. MacCentral. Available from http://www.macworld.com/article/55181/2007/02/virtualvista.html, last accessed November 4, 2008.

Conner, K. R. 1995. Obtaining Strategic Advantage from Being Imitated: When Can Encouraging "Clones" Pay? Management Science 41(2): 209-225.

Crotty, C. 1995. CompuServe GIF Uproar. MacWorld. May, 12(5), p. 38.

Cusumano, M. A., Y. Mylonadis and R. S. Rosenbloom 1992. Strategic Maneuvering and Mass-Market Dynamics - the Triumph of VHS over Beta. Business History Review 66(1): 51-94.

David, P. A. and J. A. Bunn 1988. The economics of gateway technologies and network evolution: Lessons from electricity supply history. Information Economics and Policy 3(2): 165-202.

Economides, N. 1989. Desirability of Compatibility in the Absence of Network Externalities. American Economic Review 79(5): 1165-1181.

Economides, N. and C. Himmelberg 1995. Critical Mass and Network Size with Application to the US Fax Market. Discussion Paper \# EC-95-11, Stern School of Business, New York University.

Farrell, J. and G. Saloner 1986. Installed Base and Compatibility: Innovation, Product Preannouncements, and Predation. American Economic Review 76(5): 940-955. 
Farrell, J. and G. Saloner 1992. Converters, Compatibility, and the Control of Interfaces. Journal of Industrial Economics 40(1): 9-35.

Farrell, J., C. Shapiro, R. R. Nelson and R. G. Noll 1992. Standard Setting in High-Definition Television. Brookings Papers on Economic Activity. Microeconomics 1992: 1-93.

Gallaugher, J. M. and Y.-M. Wang 2002. Understanding network effects in software markets: Evidence from Web server pricing. MIS Quarterly 26(4): 303-327.

Gandal, N. 1994. Hedonic Price Indexes for Spreadsheets and an Empirical Test for Network Externalities. RAND Journal of Economics 25(1): 160-170.

Gilder, G. (2000). Telecosm: How Infinite Bandwidth Will Revolutionize Our World. New York, NY, The Free Press.

Gohring, N. 2006. US Urges European Regulators to Lay Off Apple DRM. InfoWorld, September 14. (available from http://www.infoworld.com/article/06/09/14/HNlayoffappledrm_1.html, last accessed November 4, 2008.)

Griffiths, R. 2008. OS X Virtualization options limited for desktop users. Available from http://www.macworld.com/article/133961/2008/06/virtualosx.html, last accessed November 12, 2008.

Kauffman, R. J., J. McAndrews and W. Yu-Ming 2000. Opening the 'Black Box' of Network Externalities in Network Adoption. Information Systems Research 11(1): 61.

Liebowitz, S. J. and S. E. Margolis 1994. Network Externality: An Uncommon Tragedy. Journal of Economic Perspectives 8(2): 133-150.

Liebowitz, S. J. and S. E. Margolis (1999). Winners, Losers, and Microsoft: Competition and Antitrust in High Technology. Oakland, CA, The Independent Institute.

Liu, C. Z., C. F. Kemerer, S. A. Slaughter and M. D. Smith (2007). Standards Competition In the Presence of Conversion Technology: An Empirical Analysis of The Flash Memory Card Market, Katz Graduate School of Business, University of Pittsburgh.

Matutes, C. and P. Regibeau 1988. "Mix and Match": Product Compatibility without Network Externalities. RAND Journal of Economics 19(2): 221-234. 
McBride, S., Y.I. Kane, N. Wingfield. 2008. In Blu-ray Coup, Sony Has Opening But Hurdles, Too. Wall Street Journal, January 7, page A1.

Nash, J. F. 1950. The Bargaining Problem. Econometrica 18(2): 8.

Nicolai, J, J. Snell. 2008. Vista Home Cleared for Virtualization. MacWorld, April, 25(4), p. 32.

Ohlson, K., C. Paquet. 1997. Microsoft Savors Its Apple. InfoWorld, August 11, 19(32), p. 1 and 3.

Pell, A. 2008. Pirates' broadside rattles Nintendo. The Sunday Times (London), August 10.

Roelofs, G. 1999. PNG: The Definitive Guide. O’Reilly Publishing, Cambridge, MA.

Stokey, N. L. 1979. Intertemporal Price Discrimination. Quarterly Journal of Economics 93(3): 355-371.

Sundararajan, A. 2004. Nonlinear pricing and type-dependent network effects. Economics Letters 83(1): 107-113.

Zhu, K., K. L. Kraemer, V. Gurbaxani and X. Xu 2006. Migration to Open-Standard Interorganizational Systems: Network Effects, Switching Costs and Path Dependency. MIS Quarterly 30: 515-539. 


\section{Appendix}

Table 5: The Equilibrium of the Entire Game under Commitment to No Conversion ${ }^{\dagger}(0<\beta<3 / 5)$

\begin{tabular}{|c|c|c|c|c|}
\hline & Firm A (Stage 1) & Firm A (Stage 2) & Firm A (Overall) & Firm B (Stage 2) \\
\hline Price & $P_{A 1}^{N^{*}}=\frac{38-33 \beta}{26} \downarrow$ & $P_{A 1}^{N^{*}}=\frac{38-33 \beta}{26} \downarrow$ & $\mathrm{n} / \mathrm{a}$ & $P_{B}^{N^{*}}=\frac{11-14 \beta}{13} \downarrow$ \\
\hline $\begin{array}{c}\text { Market } \\
\text { Share }\end{array}$ & $M S_{A 1}^{N^{*}}=\frac{6+3 \beta}{26(1-\beta)}$ & $M S_{A 2}^{N^{*}}=\frac{9-15 \beta}{26(1-\beta)} \downarrow$ & $M S_{A}^{N^{*}}=\frac{15-12 \beta}{26(1-\beta)}$ & $M S_{B}^{N^{*}}=\frac{9-15 \beta}{26(1-\beta)} \downarrow$ \\
\hline Profit & $\Pi_{A 1}^{N^{*}}=\frac{3\left(76-28 \beta-33 \beta^{2}\right)}{676(1-\beta)}$ & $\Pi_{A 2}^{N^{*}}=\frac{9\left(9-30 \beta+25 \beta^{2}\right) \downarrow}{338(1-\beta)} \downarrow$ & $\Pi_{A}^{N^{*}}=\frac{3\left(10-16 \beta+9 \beta^{2}\right)}{52(1-\beta)}$ & $\Pi_{B}^{N^{*}}=\frac{\left.121-308 \beta+196 \beta^{2}\right) \downarrow}{338(1-\beta)}$ \\
\hline
\end{tabular}

${ }^{\dagger}$ The arrows in the table correspond to the comparative statics results of prices, market shares and profits with respect to $\beta$.

${ }^{\ddagger} \Pi_{A}$ is decreasing in $\beta$ when $0<\beta<\frac{(3-\sqrt{3})}{3}$ and is increasing in $\beta$ when $\frac{(3-\sqrt{3})}{3}<\beta<\frac{3}{5}$.

Table 6: The Equilibrium of the Entire Game under Commitment to Partial Conversion ${ }^{\ddagger}\left(C^{*}=C_{\max }\right)$

\begin{tabular}{|c|c|c|c|}
\hline & Firm A (Stage 1) & Firm A (Stage 2) & Firm B (Stage 2) \\
\hline \multirow{2}{*}{ Price } & $P_{A 1}^{P^{*}}=\frac{912-2368 \beta+2304 \beta^{2}-992 \beta^{3}+159 \beta^{4}}{2\left(312-648 \beta+448 \beta^{2}-103 \beta^{3}\right)}$ & $P_{A 2}^{P^{*}}=\frac{432-1336 \beta+1496 \beta^{2}-772 \beta^{3}+127 \beta^{4}}{2\left(312-648 \beta+448 \beta^{2}-103 \beta^{3}\right)}$ & \multirow{2}{*}{$P_{B}^{P^{*}}=\frac{528-1496 \beta+1536 \beta^{2}-682 \beta^{3}+111 \beta^{4}}{2\left(312-648 \beta+448 \beta^{2}-103 \beta^{3}\right)}$} \\
\hline \multirow{2}{*}{$\begin{array}{c}\text { Market } \\
\text { Share }\end{array}$} & $M S_{A 1}^{P^{*}}=\frac{4\left(18-15 \beta-4 \beta^{2}+4 \beta^{3}\right)}{\left(312-648 \beta+448 \beta^{2}-103 \beta^{3}\right)}$ & $M S_{A 2}^{P^{*}}=\frac{216-560 \beta+4684 \beta^{2}-127 \beta^{3}}{2\left(312-648 \beta+448 \beta^{2}-103 \beta^{3}\right)}$ & \multirow{2}{*}{$M S_{B}^{P^{*}}=\frac{264-616 \beta+460 \beta^{2}-111 \beta^{3}}{2\left(312-648 \beta+448 \beta^{2}-103 \beta^{3}\right)}$} \\
\cline { 2 - 2 } & $M S_{A}^{P^{*}}=\frac{360-732 \beta-196 \beta^{2}+183 \beta^{3}}{2\left(312-648 \beta+448 \beta^{2}-103 \beta^{3}\right)}$ & \\
\hline \multirow{2}{*}{ Profit } & $\Pi_{A}^{P^{*}}=\Pi_{A 1}^{P^{*}}+\Pi_{A 2}^{N^{*}}+\frac{J^{P^{*}}-J^{N^{*}}}{2}=\frac{4320-8904 \beta+6952 \beta^{2}-2516 \beta^{3}+373 \beta^{4}}{24\left(312-648 \beta+448 \beta^{2}-103 \beta^{3}\right)}$ & $\Pi_{B}^{P^{*}}=\frac{2190-8721 \beta+358 \beta^{2}-3145 \beta^{3}+297 \beta^{4}}{4\left(312-648 \beta+448 \beta^{2}-103 \beta^{3}\right)^{2}}$ \\
\hline
\end{tabular}

\$ when $\beta<0.717, C_{\text {int }}^{P}>C_{\max }^{P}$ and $C^{p^{*}}=C_{\max }^{P}=\frac{360 \beta-680 \beta^{2}+436 \beta^{3}-95 \beta^{4}}{2\left(312-648 \beta+448 \beta^{2}-103 \beta^{3}\right)}$.

Table 7: The Equilibrium of the Entire Game under Commitment to Partial Conversion ${ }^{\dagger}\left(C^{*}=C_{\text {int }}\right)$

\begin{tabular}{|c|c|c|c|}
\hline & Firm A (Stage 1) & Firm A (Stage 2) & Firm B (Stage 2) \\
\hline \multirow{2}{*}{ Price } & $P_{A 1}^{P^{*}}=\frac{159-193 \beta+58 \beta^{2}}{58-37 \beta}$ & $P_{A 2}^{P^{*}}=\frac{112-166 \beta+57 \beta^{2}}{58-37 \beta}$ & $P_{B}^{P^{*}}=\frac{-18+43 \beta-19 \beta^{2}}{58-37 \beta}$ \\
\hline \multirow{2}{*}{$\begin{array}{c}\text { Market } \\
\text { Share }\end{array}$} & $M S_{A 1}^{P^{*}}=\frac{11-\beta}{58-37 \beta}$ & $M S_{A 2}^{P^{*}}=\frac{112-166 \beta+57 \beta^{2}}{116-132 \beta+37 \beta^{2}}$ & $M S_{B}^{P^{*}}=\frac{18-43 \beta+19 \beta^{2}}{116-132 \beta+37 \beta^{2}}$ \\
\cline { 2 - 3 } & $M S_{A}^{P^{*}}=\frac{134-175 \beta-56 \beta^{2}}{(2-\beta)(58-37 \beta)}$ & \\
\hline \multirow{2}{*}{ Profit } & $\Pi_{A}^{P^{*}}=\Pi_{A 1}^{P^{*}}+\Pi_{A 2}^{P^{*}}+\frac{J^{P^{*}}-J^{N^{*}}}{2}=\frac{-800+12744 \beta-712 \beta^{2}+139 \beta^{3}}{6(2-\beta)(58-37 \beta)}$ & $\Pi_{B}^{P^{*}}==\frac{29548-78602 \beta+77526 \beta^{2}-33460 \beta^{3}+5339 \beta^{4}}{6(2-\beta)(58-37 \beta)^{2}}$ \\
\hline
\end{tabular}

$\dagger$ when $0.958<\beta<1, C_{\mathrm{int}}^{P}<C_{\max }^{P}$ and $C^{p *}=C_{\mathrm{int}}^{P}=\frac{206-289 \beta+95 \beta^{2}}{58-37 \beta}$. 


\section{Derivation of the Entries of Table 5 - No Conversion}

The third stage prices, market shares, and profits are given by $(8)-(13)$. Given that the incumbent is committed to no conversion, the location of consumer $i^{*}$ who is indifferent between buying A in stages 2 and 3 is determined as follows:

$$
r+2 i^{*}+\beta\left(1-i^{*}\right)+\beta\left(1-s^{*}\right)-P_{A 1}^{N}=r+i^{*}+\beta\left(1-s^{*}\right)-P_{A 2}^{N} \Rightarrow P_{A 1}^{N}=i^{*}+P_{A 2}^{N}+\beta\left(1-i^{*}\right)
$$

In stage 2 the incumbent chooses $i^{*}$ to maximize its profits over stages 2 and 3 as follows:

$$
\underset{i^{*}}{\operatorname{Max} \Pi_{A}^{N}}=\left(1-i^{*}\right)\left[i^{*}+\frac{\left(4 i^{*}-1\right)(1-\beta)}{3}+\beta\left(1-i^{*}\right)\right]+\frac{\left(4 i^{*}-1\right)^{2}(1-\beta)}{18}
$$

Optimizing with respect to $i^{*}$ yields the solution in Table 5 .

\section{Derivation of the Entries of Tables 6 and 7 -Partial Conversion}

The third stage prices, market shares, and profits are given in Table 2, where $C^{P}$ is still given by either (16) or (17). The indifferent consumer $i^{*}$ is expressed as in (26), given that A's consumers do not have access to B's network. Optimization with respect to $i^{*}$ over the aggregate profits of firm A in stages 2 and 3 yields the entries in Tables 6 and 7.

Table 8: The Equilibrium of the Entire Game under Free Full Conversion

\begin{tabular}{|c|c|c|c|c|}
\hline & Firm A (Stage 1) & Firm A (Stage 2) & Firm A (Overall) & Firm B (Stage 2) \\
\hline Price & $P_{A 1}^{F F^{*}}=\frac{19-15 \beta}{13-9 \beta}$ & $P_{A 2}^{F F^{*}}=\frac{9(1-\beta)}{13-9 \beta}$ & $\mathrm{n} / \mathrm{a}$ & $P_{B}^{F F^{*}}=\frac{11-9 \beta}{13-9 \beta}$ \\
\hline $\begin{array}{c}\text { Market } \\
\text { Share }\end{array}$ & $M S_{A 1}^{F F^{*}}=\frac{3}{13-9 \beta}$ & $M S_{A 2}^{F F^{*}}=\frac{9(1-\beta)}{2(13-9 \beta)}$ & $M S_{A}^{F F^{*}}=\frac{3(5-2 \beta)}{2(13-9 \beta)}$ & $M S_{B}^{F F^{*}}=\frac{11-9 \beta}{2(13-9 \beta)}$ \\
\hline Profit & $\Pi_{A 1}^{F F^{*}}=\frac{3(19-15 \beta)}{(13-9 \beta)^{2}}$ & $\Pi_{A 2}^{F F^{*}}=\frac{81\left(1-2 \beta+\beta^{2}\right)}{2(13-9 \beta)^{2}}$ & $\Pi_{A}^{F F^{*}}=\frac{3(5-3 \beta)}{2(13-9 \beta)}$ & $\Pi_{B}^{F F^{*}}=\frac{\left.121-198 \beta+81 \beta^{2}\right)}{2(13-9 \beta)^{2}}$ \\
\hline $\begin{array}{c}\text { Joint } \\
\text { Profits }\end{array}$ & \multicolumn{4}{|c|}{$J^{F F^{*}}=\frac{158-225 \beta+81 \beta^{2}}{(13-9 \beta)^{2}}$} \\
\hline
\end{tabular}

Profit comparison of Free Full Conversion with No Conversion:

$$
\begin{aligned}
& \Pi_{A}^{F F^{*}}-\Pi_{A}^{N^{*}}=\frac{9 \beta\left(30-61 \beta+27 \beta^{2}\right)}{52(1-\beta)(13-9 \beta)}>0 \text { when } 0<\beta<0.723 \\
& \Pi_{B}^{F F^{*}}-\Pi_{B}^{N^{*}}=\frac{26455 \beta-67846 \beta^{2}+57123 \beta^{3}-15876 \beta^{4}}{338(1-\beta)(13-9 \beta)^{2}}>0 \text { when } 0<\beta<0.928 \\
& J^{F F^{*}}-J^{N^{*}}=\frac{98540 \beta-260063 \beta^{2}+219546 \beta^{3}-60183 \beta^{4}}{676(1-\beta)(13-9 \beta)^{2}}>0 \text { when } 0<\beta<0.808
\end{aligned}
$$




\section{Proof of Lemma 2}

Differentiating $J^{P}\left(i^{*}, C^{P}\right)=\frac{5 i^{* 2}(2-\beta)^{2}-2 i^{*}(2-\beta)\left(1-C^{P}\right)+2\left(1-C^{P}\right)^{2}}{9(2-\beta)}+\frac{C^{P}\left[i^{*}(2-\beta)+\left(1-C^{P}\right)\right]}{3(2-\beta)}$ from Table 2

with respect to $C^{P}$ yields $\frac{10 i^{*}-5 i^{*} \beta-2 C^{P}-1}{9(2-\beta)}=0$. Thus we obtain the interior solution $C_{\mathrm{int}}^{P}=\frac{5 i^{*}(2-\beta)-1}{2}$

as shown in (16). Note that in order for the Partial Conversion equilibrium to hold, the equilibrium price of the converter must be no more than the maximum willingness to pay on the part of consumers $\left(C_{\max }^{P}=\beta M S_{A}^{P}\right)$, that is, $C^{P} \leq C_{\max }^{P}=\beta M S_{A}^{P}$. Solving this inequality yields:

$$
i^{*}<\frac{1+\beta-\beta^{2}}{(2-\beta)(5-3 \beta)} .
$$

Therefore, when (27) holds, the optimal converter price is given by (16). Moreover, all prices derived in Table 2 must be positive, hence the remaining market size $i^{*}$ must satisfy $1>i^{*}>\frac{1-C^{P}}{2(2-\beta)}$, Substituting (16) into this inequality yields $1>i^{*}>\frac{1}{3(2-\beta)}$. Combining the last inequality with (27) yields that the interior solution is possible only in the region specified in the first part of Lemma 2.

When (27) does not hold $\left(C_{\mathrm{int}}^{P}>C_{\max }^{P}\right.$ ), the constraint is binding and the optimal price of the converter is given by: $C^{P^{*}}=C_{\max }^{P}=\beta M S_{A}^{P}=\frac{\beta\left[(5-3 \beta)-i^{*}(2-\beta)\right]}{2(3-2 \beta)}$ as shown in (17). Substituting (17) into the inequality $1>i^{*}>\frac{1-C^{P}}{2(2-\beta)}$ yields $1>i^{*}>\frac{1-\beta}{4-3 \beta}$. Combining this inequality with $i^{*}>\frac{1+\beta-\beta^{2}}{(2-\beta)(5-3 \beta)}$ yields the regions reported in the second half of Lemma 2

\section{Proof of Observation 1:}

(i) From (9) and Tables 2 and 3 , we have, $P_{B}^{N}=\frac{2 i^{*}+1-2 i^{*} \beta-\beta}{3}, P_{B}^{P}=\frac{2 i^{*}+1-2 \beta-C^{P}}{3}$, and $P_{B}^{F}=\frac{2 i^{*}+1}{3}$. Let $x=P_{B}^{P}-P_{B}^{N}=\frac{2 i^{*} \beta-\beta-C^{P}}{3}$. When $C^{P^{*}}=C_{\max }^{P}, \quad x=\frac{\beta(1-\beta)+i^{*} \beta(8-5 \beta)}{6(3-2 \beta)}>0$ always holds when $0<\beta<1$. When $C^{P^{*}}=C_{I N T}^{P}, x=\frac{1-10 i^{*}+2 \beta+7 i^{*} \beta}{6}$. In order for $x>0$ to hold, it requires that $0<i^{*}<\frac{2 \beta+1}{10-7 \beta}$

From (27) we have $i^{*}<\frac{1+\beta-\beta^{2}}{(2-\beta)(5-3 \beta)}<\frac{2 \beta+1}{10-7 \beta}$, therefore, $x>0$ also holds when $C^{P^{*}}=C_{I N T}^{P}$. Moreover, 
since $P_{B}^{F}-P_{B}^{P}=\frac{i^{*} \beta+C^{P}}{3}>0$, we have $P_{B}^{F}>P_{B}^{P}>P_{B}^{N}$.

(ii) Let $\Pi_{A B}$ denote firms' joint product revenue in stage 2, From (14) and Tables 2 and 3, we have:

$\Pi_{A B}^{N}=\frac{(1-\beta)\left(10 i^{* 2}-2 i^{*}+1\right)}{9}, \Pi_{A B}^{P}=\frac{5 i^{* 2}(2-\beta)^{2}-2 i^{*}(2-\beta)\left(1-C^{P}\right)+2\left(1-C^{P}\right)^{2}}{9(2-\beta)}$ and $\Pi_{A B}^{F}=\frac{1-2 i^{*}+10 i^{* 2}}{9}$.

Let $z=\Pi_{A B}^{F}-\Pi_{A B}^{P}=\frac{C^{P}\left(4-2 C^{P}-4 i^{*}+2 i^{*} \beta\right)-\beta\left(1+5 i^{*}-10 i^{* 2}\right)}{9(2-\beta)}$, and

$y=\Pi_{A B}^{P}-\Pi_{A B}^{N}=\frac{C^{P}\left(-4+2 C^{P}+4 i^{*}-2 i^{*} \beta\right)+\beta\left(3-4 i^{*}+10 i^{* 2}\right)-\beta^{2}\left(1-2 i^{*}+5 i^{* 2}\right)}{9(2-\beta)}$

When $C^{P^{*}}=C_{\max }^{P}, \quad y=\frac{\beta\left(21-42 i^{*}+102 i^{* 2}\right)-\beta^{2}\left(28+56 i^{*}+136 i^{* 2}\right)+9 \beta^{3}\left(1-2 i^{*}+5 i^{* 2}\right)}{18(3-2 \beta)^{2}}>0$, and

$z=\frac{\beta\left(-3+6 i^{*}+78 i^{* 2}\right)+\beta^{2}\left(4-8 i^{*}-104 i^{* 2}\right)+\beta^{3}\left(1-2 i^{*}-35 i^{* 2}\right)}{18(3-2 \beta)^{2}}>0$. When $C^{P^{*}}=C_{I N T}^{P}$, we also obtain that

$y=\frac{-5+64 i^{*}-140 i^{* 2}-\beta\left(2+32 i^{*}-160 i^{* 2}\right)-45 i^{* 2} \beta^{2}}{18(2-\beta)}>0$, and

$z=\frac{5-64 i^{*}+140 i^{* 2}+6 \beta\left(1+4 i^{*}-20 i^{* 2}\right)-2 \beta^{2}+4 i^{*} \beta^{2}+25 i^{* 2} \beta^{2}}{18(2-\beta)}>0$ in the region of $i^{*}$ values consistent with $C^{P^{*}}=C_{I N T}^{P}$. Hence $\Pi_{A B}^{F}>\Pi_{A B}^{P}>\Pi_{A B}^{N}$.

\section{Proof of Observation 2:}

Let $\Pi_{C}$ denote the proceeds from the sale of the converters. From Tables 2 and 3, we have: $\Pi_{C}^{F}=\beta\left(\frac{2 i^{*}+1}{6}\right)$ and $\Pi_{C}^{P}=\frac{C^{P}\left[i^{*}(2-\beta)+\left(1-C^{P}\right)\right]}{3(2-\beta)}$. Substituting (16) and (17) into $\Pi_{C}^{P}$ yields $\Pi_{C}^{P}=\frac{\left(1-10 i^{*}+5 i^{*} \beta\right)\left(-3+10 i^{*}-5 i^{*} \beta\right)}{12(2-\beta)} \quad\left(\right.$ when $\left.\quad C^{P^{*}}=C_{I N T}^{P}\right)$ and $\Pi_{C}^{P}=\frac{\left.\left(1+2 i^{*}-\beta-i^{*} \beta\right)\left(5 \beta-2 i^{*} \beta-3 \beta^{2}+i^{*} \beta^{2}\right)\right]}{4(3-2 \beta)^{2}}$

(when $C^{P^{*}}=C_{\max }^{P}$ ). It can be shown that $\Pi_{C}^{F}>\Pi_{C}^{P}$ for any feasible ranges of $C^{P^{*}}$.

\section{Proof of Proposition 4:}

We designate the profits that accrue in each case by $\Pi_{A}^{F}, \Pi_{A}^{P}, \Pi_{A}^{N}$ and $\Pi_{A}^{D}$ (corresponding to Full, Partial, and No Conversion, and to Dominance, respectively), and compare the overall profits of the incumbent under these four regimes. We find that when $0<\beta<0.717, \Pi_{A}^{F}>\Pi_{A}^{P}>\Pi_{A}^{N}>\Pi_{A}^{D}$, when $0.717<\beta<0.982, \Pi_{A}^{F}>\Pi_{A}^{D}>\Pi_{A}^{P}$, and when $0.982<\beta<1, \quad \Pi_{A}^{D}>\Pi_{A}^{F}>\Pi_{A}^{P}$, where the ranking is valid when the 
corresponding commitment regimes are feasible. This outcome leads to the result reported in Proposition 4.

\section{Proof of Proposition 5:}

As shown in (23), Social welfare consists of the sum of three components: product reservation price $r$, the average network benefits, and product differentiation $(P D)$ benefits. Since $r$ and $P D$ are the same across different types of equlibria. Social welfare is maximized when the average network effects benefits are maximized. As is obvious from (23), Full Conversion yields the largest average network effect benefits. Hence social welfare is maximized with Full Conversion, which is given by:

$$
T S^{F}=r+\left[\beta+\beta\left(1-i^{*}\right)^{2}\right]+s^{*}\left(1-\frac{s^{*}}{2}\right)+\frac{i^{* 2}-s^{* 2}}{2}+\left(1-i^{* 2}\right), \text { s.t. } 0<s^{*} \leq i^{*}<1 .
$$

Solving the first order condition with respect to $i^{*}$ yields $i^{*}=\frac{2 \beta}{2 \beta-1}$. When $\beta<1 / 2, i^{*}<0$, implying that the lower bound constraint is binding and $i^{*}$ assumes the smallest possible value, namely, $i^{*}=s^{*}$. When $\beta>1 / 2, i^{*}>1$, implying again a corner solution. Substituting $i^{*}=s^{*}$ into the objective function and differentiating with respect to $i^{*}$ yields the solution reported in Proposition 5. It is positive only if $\beta<1 / 2$.

\section{Derivation of the Equation (24)}

\section{$\underline{\text { No Conversion }}$}

With No Conversion the consumer $s^{*}$ who is indifferent between A and B's technologies in stage 2 satisfies the equation:

$$
r+k s^{*}+k \beta\left(1-s^{*}\right)-P_{A 2}^{N}=r+k\left(1-s^{*}\right)+k \beta s^{*}-P_{B}^{N} \Rightarrow s^{*}=\frac{k(1-\beta)+P_{A 2}^{N}-P_{B}^{N}}{2 k(1-\beta)}
$$

The firms choose $P_{A 2}^{N}$ and $P_{B}^{N}$ to maximize the following objective functions:

$$
\operatorname{Max}_{P_{A 2}^{N}} k P_{A 2}^{N}\left(i^{*}-\frac{k(1-\beta)+P_{A 2}^{N}-P_{B}^{N}}{2 k(1-\beta)}\right) ; \quad \operatorname{Max}_{P_{B}^{N}} k P_{B}^{N}\left(\frac{k(1-\beta)+P_{A 2}^{N}-P_{B}^{N}}{2 k(1-\beta)}\right) .
$$

Solving the above yields: $P_{A 2}^{N}=\frac{k(1-\beta)\left(4 i^{*}-1\right)}{3} ; \quad P_{B}^{N}=\frac{k(1-\beta)\left(2 i^{*}+1\right)}{3}$, 
which is $k$ times the prices obtained in (8) and (9) for the No Conversion case. Substituting into the expression for $s^{*}$ yields market shares identical to those obtained when $k=1$ (i.e. (10) and (11)). As a result, second stage product profits are $k$ times the expressions obtained in (12) - (14).

The consumer $i^{*}$ who is indifferent between buying A in stages 1 and 2 satisfies the equation: $r+(k+1) i^{*}+\beta\left(1-i^{*}\right)+k \beta\left(1-s^{*}\right)-P_{A 1}^{N}=r+k i^{*}+k \beta\left(1-s^{*}\right)-P_{A 2}^{N}$, thus yielding $P_{A 1}^{N}=i^{*}+P_{A 2}^{N}+\beta\left(1-i^{*}\right)$, where $P_{A 2}^{N}$ is derived to equal $k$ times expressions (8).

\section{Full Conversion}

With Full Conversion the consumer $s^{*}$ who is indifferent between A and B's technologies in stage 2 satisfies the equation: $r+k s^{*}+k \beta-P_{A 2}^{F}=r+k\left(1-s^{*}\right)+k \beta s^{*}-P_{B}^{F}$. Hence $s^{*}=\frac{k+P_{A 2}^{F}-P_{B}^{F}}{2 k}$ and the Nash equilibrium prices and second stage profits are $k$ multiples of the entries in Table 3 . The proceeds from the sale of converters is also $k$ times the proceeds for the case $k=1$, since the price is determined to extract the conversion benefits that accrues to the consumers, namely $C^{F^{*}}=k \beta M S_{B}^{F^{*}}$. Hence the aggregate second stage payoff of the firms is $k$ times expression (20).

The consumer $i^{*}$ who is indifferent between buying A in stages 1 and 2 satisfies the equation: $r+(k+1) i^{*}+\beta\left(1-i^{*}\right)+k \beta-P_{A 1}^{F}=r+k i^{*}+k \beta-P_{A 2}^{F}$, still yielding $P_{A 1}^{F}=i^{*}+P_{A 2}^{F}+\beta\left(1-i^{*}\right)$ as the relationship between $P_{A 1}^{F}$ and $P_{A 2}^{F}$, where $P_{A 2}^{F}$ is $k$ times the expression obtained in Table 3 .

The above discussion leads directly to (24). 